NASA Technical_Memorandum 102496

\title{
Navier-Stokes Analysis of Turbine Blade Heat Transfer
}

R.J. Boyle

Lewis Research Center

Cleveland, Ohio

Prepared for the

35th International Gas Turbine and Aeroengine Congress and Exposition sponsored by the American Society of Mechanical Engineers Brussels, Belgium, June 11-14, 1990

\section{N/SA}

(NACA-TM-102495) NAVIER-STTKFS ANALYSIS OF

$\sqrt{90-21300}$ TUROINE BLADE HEAT TRANGFFR (NASA) $21 \mathrm{P}$
CSCL 200 
$=$ 


\title{
NAVIER-STOKES ANALYSIS Of TURBINE BLADE HEAT TRANSFER
}

\author{
R. J. Boyle \\ NASA Lewis Research Center \\ Cleveland, Ohio 44135
}

\begin{abstract}
Comparisons with experimental heat transfer and surface pressures were made for seven turbine vane and blade geometries using a quasi-three-dimensional thinlayer Navier-Stokes analysis. Comparisons are made for cases with both separated and unseparated flow over a range of Reynolds numbers and freestream turbulence intensities. The analysis used a modified BaldwinLomax turbulent eddy viscosity model. Modifications were made to account for the effects of: 1) freestream turbulence on both transition and leading edge heat transfer; 2) strong favorable pressure gradients on relaminarization; and 3) variable turbulent Prandtl number on heat transfer. In addition, the effect on heat transfer of the near-wall model of Deissler is compared with the Van Driest model.
\end{abstract}

\section{Nomenclature}

A - Area

$A^{+}$. Damping coefficient

$C$ - Chord

$C_{f}$ - Friction factor

$C_{p}$ - Specific heat at constant pressure

$k$ - Thermal conductivity

$\ell$ - Length scale

$m$ - Meridional direction

$P$ - Pressure

$P^{+}$- Pressure gradient, $\left(\nu U_{e}^{3} / \rho\right)\left(C_{f} / 2\right)^{3 / 2} \partial P / \partial s$

Pr - Prandtl number

$Q$ - Dynamic head, $\rho U^{2} / 2$

$R e$ - Unit Reynolds number, subscript gives length

$r$ - Radius

$s$ - Surface distance

$s^{+}$- Normalized surface distance, $\left(s U_{e} / \nu\right) \sqrt{C_{f} / 2}$

$S t$ - Stanton no., $k|\partial T / \partial y|_{\mathrm{W}} /\left[(\rho U)_{\mathrm{IN}} C_{p}\left(T_{\mathrm{IN}}^{\prime}-T_{\mathrm{W}}\right)\right]$

$T$ - Temperature

$T u$ - Turbulence intensity

$U$ - Inviscid velocity

$v$ - Velocity in flow solution

$x$ - Axial direction

$Y$ - Pressure coefficient, $Y=\left(P_{\mathrm{IN}}^{\prime}-P\right) / Q_{\mathrm{IN}}$

$y$ - Perpendicular distance from surface

$y^{+}$- Normalized surface distance, $\left(y U_{e} / \nu\right) \sqrt{C_{f} / 2}$ $\gamma_{t}$ - Intermittency factor

$\delta$ - Full boundary layer thickness

$\epsilon_{M}$ - Eddy viscosity

$\eta$ - Direction outward from blade

$\theta$ - Momentum thickness

$\kappa$ - Von Karman's constant, $\kappa=\mathbf{0 . 4}$

$\lambda$ - Momentum thickness pressure gradient parameter

$\mu$ - Dynamic viscosity

$\nu$ - Kinematic viscosity

$\xi$ - Direction around blade

$\rho$ - Density

$\phi$ - Ratio of axial velocity to mean blade speed

$\omega$ - Vorticity, $\partial v / \partial y$ Subscripts

$e$ - Edge of boundary layer

EX - Exit

$f$ - End of transition

$i$ - Start of transition

IN - Inlet

$m$ - Meridional

$\mathrm{s}$ - Distance along blade

t - Turbulent

$x$ - Axial

w - Wall

$\theta$ - Tangential direction or

- Momentum thickness

Superscript

' - Total conditions

\section{INTRODUCTION}

Accurate predictions of turbine blade heat transfer are important, especially as turbine inlet temperature increases. One approach to predicting blade heat transfer is to use a boundary layer analysis such as the STAN5 analysis of Crawford and Kays ${ }^{(1)}$. However, this approach cannot be used to predict heat transfer beyond the point of separation. Also, because of the necessity of specifying a starting condition with boundary layer analyses, the heat transfer predictions in the leading edge region may be in error. An alternate approach to predicting turbine blade heat transfer, especially useful when separation occurs, is the use of Navier-Stokes analyses. Both two- and three-dimensional Navier-Stokes 
analyses have been developed ${ }^{(2-6)}$. The emphasis in these analyses has been on obtaining accurate aerodynamic results. This paper discusses the results of turbine blade heat transfer predictions using the quasithree-dimensional, thin-layer Navier-Stokes analysis developed by Chima ${ }^{(2)}$. The modifications described by Chima, Turkel, and Schaffer ${ }^{(7)}$ were used.

The analysis developed by Chima incorporated the Baldwin and Lomax ${ }^{(8)}$ turbulence model. This model has several attractive features from a computational standpoint. However, the model does not account for several factors known to influence turbine blade heat transfer. Among these factors are: (1) the effect of freestream turbulence on leading edge heat transfer and on the location of transition, (2) the effect of boundary layer relaminarization on heat transfer, and (3) the effect of a variable turbulent Prandtl number. The turbulence model was modified to include models for these various effects. Also, the near-wall damping model of Deissler $^{(9)}$ was compared with Van Driest's model.

The solution procedure for Navier-Stokes analyses differ from boundary layer analyses in several respects. Before alternate models can be evaluated, it is necessary to verify that other factors do not cloud the comparisons. In boundary layer analyses all of the solution domain is confined to the boundary layer region. For Navier-Stokes analyses, however, only a small fraction of the blade-to-blade grid may be within the boundary layer regions. Also, boundary layer analyses are marching type analyses, while Navier-Stokes analyses require the solution of the entire flow field in an iterative manner. One purpose of this paper is to show results for different grid and iteration parameters to demonstrate the values needed so that comparisons are independent of these parameters.

The appropriateness of the heat transfer models are shown by comparisons with experimental data. Comparisons were made for each of the three blade rows in the stage-and-a-half data of Dring, Blair, Joslyn, Power, and Verdon ${ }^{(10-13)}$, the two stators of Hylton, Mihelc, Turner, Nealy, and York ${ }^{(14)}$, as well as the stator and rotor data of Hippensteele, Russell, and Torres ${ }^{(15-16)}$. These sources of data result in comparisons over a wide range of Reynolds numbers and turbulence intensities. The Navier-Stokes analyses have the ability to calculate heat transfer when there is separation. Therefore, comparisons are made for cases with attached flows and for cases with separated flows. With respect to the thermal modeling there are three objectives. The first is to show that the accepted models for boundary layer analyses are appropriate for Navier-Stokes analyses as well. The second is to choose a model which gives reasonably good agreement for the cases examined. Since improved models for turbine blade heat transfer are continually being developed, it is not the purpose of this paper to demonstrate that a particular model gives good agreement with data for every case. However, to demonstrate the aspects of the Navier-Stokes heat transfer predictions it is necessary to choose a reasonably accurate model. The third objective is to show the effects of various assumptions on turbine blade heat transfer. Since, some of these assumptions show better agreement than the base-case model, a recommendation is made for the appropriate prediction methodology.

\section{DESCRIPTION of ANALYSIS}

Basic flow analysis. The analysis used the flow solver developed by Chima ${ }^{(2)}$. The solver is for either inviscid or viscous quasi-three-dimensional flow, wherein the variation of the stream sheet thickness is accounted for. The variation in stream sheet thickness is determined from a hub-to-shroud flow analysis using a program such as MERIDL of Katsanis ${ }^{(17)}$. The viscous analysis of reference 2 employs the thin-layer NavierStokes assumptions, wherein the streamwise derivatives of the viscous terms are neglected. A four-stage RungeKutta algorithm with residual smoothing and variable time steps is used. The equations used are given in reference 2. The heat transfer predictions are dependent on an effective viscosity, $\mu_{\mathrm{eff}}$, and an effective Prandt] number, $P t_{\text {eff }}$. These quantities are given by:

$$
\begin{gathered}
\mu_{\mathrm{eff}}=\mu_{\text {laminar }}+\mu_{\text {turbulent }}=\rho\left(\nu+\epsilon_{M}\right) \\
\operatorname{Pr}_{\mathrm{eff}}=\frac{1+\left(\frac{\epsilon_{M}}{\nu}\right)}{1 / \operatorname{Pr}+\left(\frac{\epsilon_{M}}{\nu}\right) / \operatorname{Pr}_{t}}
\end{gathered}
$$

The following description focuses on the calculation of $\mu_{\text {turbulent, }}$ and the turbulent Prandtl number, $P r_{t}$.

Baldwin-Lomax turbulence model. This model is a two-layer algebraic eddy viscosity model. The eddy viscosity is found from:

$$
\mu_{t}=\begin{array}{ll}
\left(\mu_{t}\right)_{\text {inner }} & \text { if } \mathrm{y} \leq \mathrm{y}_{\text {crossover }} \\
\left(\mu_{t}\right)_{\text {outer }} & \text { if } \mathrm{y}>\mathrm{y}_{\text {crossover }}
\end{array}
$$

where $y_{\text {crossover }}$ is given by the minimum value of $y$ for which $\left(\mu_{t}\right)_{\text {inner }}=\left(\mu_{t}\right)_{\text {outer }}$. The inner and outer values are:

$$
\begin{gathered}
\left(\mu_{t}\right)_{\text {inner }}=\rho\left(\kappa y\left(1-e^{-y^{+} / A^{+}}\right)\right)^{2}|\omega| \\
\left(\mu_{t}\right)_{\text {outer }}=C_{\text {outer }} \rho F_{\text {WAKE }} F_{\text {KLEB }}
\end{gathered}
$$

$A^{+}=26$, and $C_{\text {outer }}=0.0269$. $F_{\mathrm{WAKE}}$ is given by:

$$
F_{\mathrm{WAKE}}=\min \left(y_{\max } F_{\max }, 0.25 y_{\max } v_{\mathrm{DIF}}^{2} / F_{\max }\right)
$$

The quantities $y_{\max }$ and $F_{\max }$ are found from:

$$
I(y)=y|\omega|\left(1-e^{-y^{+} / A^{+}}\right)
$$


$y_{\max }$ is the $y$ value for which $F(y)$ is a maximum. $F_{\mathrm{KLEB}}$ is given by:

$$
F_{\mathrm{KLEB}}=\left[1+5.5\left(0.3 y / y_{\max }\right)^{6}\right]^{-1}
$$

The term $v_{D I F}$ is given by:

$$
v_{\mathrm{DIF}}=\left(\sqrt{v_{\theta}^{2}+v_{m}^{2}}\right)_{\max }-\left(\sqrt{v_{\theta}^{2}+v_{m}^{2}}\right)_{\min }
$$

Except for wakes, the second term is zero.

When $\left(\mu_{t}\right)_{\text {MAX IN PROFILE }} / \mu_{\infty} \geq 14$, transition occurs. $\mu_{\infty}$ is the freestream molecular viscosity. The turbulent Prandtl number, $P_{r_{t}}=0.9$.

Turbulent Prandtl number model. As an alternative to the constant $P_{r_{t}}$ used in the Balwin-Lomax model Crawford and Kays ${ }^{(1)}$ give $P r_{t}$ as a function of the distance from the wall. This model is referred to as the Kays and Moffat model, and expresses $P_{r_{t}}$ as:

$$
\begin{gathered}
\operatorname{Pr}_{t}=\left[\frac{0.5}{P r_{t \infty}}+\frac{0.2 \epsilon_{M} P r}{\nu \sqrt{P r_{t \infty}}}\right. \\
\left.-0.04\left(\frac{\epsilon_{M} P r}{\nu}\right)^{2}\left(1.0-e^{-\left(\nu \sqrt{P r_{t \infty} / \epsilon_{M} / P r}\right.}\right)\right]^{-1}
\end{gathered}
$$

The recommended value for $\operatorname{Pr}_{t \infty}$ is 0.86 . Figure 1 shows the variation of $\operatorname{Pr}_{t}$ with distance from the wall, $y^{+}$, for a flat plate boundary layer. Pai and Whitelaw ${ }^{(18)}$ used a linear variation in $P_{r_{t}}$ with a value of 1.75 at the wall and decreasing to 0.5 at the edge of the boundary layer. The model of Kays and Moffat was used because $\operatorname{Pr}_{t}$ smoothly varied into the commonly used freestream value.

Eddy viscosity model. In the near wall region the most commonly used eddy viscosity model is the Van Driest model. This model is incorporated into the Baldwin-Lomax model, and is given by equation 4 . Other models have been proposed for the near-wall region, White ${ }^{(19)}$. One of these is Deissler's ${ }^{(9)}$, where the eddy viscosity is given as:

$$
\epsilon_{M}=n^{2} v y\left(1-e^{-n^{2} v y / \nu}\right)
$$

where $n=0.124$. The form of equations 4 and 11 is very different. Away from the wall, the eddy viscosity becomes proportional to $y^{2}|\omega|$ in the VanDriest model. In Deissler's model the ratio of eddy to molecular viscosity is proportional to the Reynolds number based on distance from the wall. Figure 2 shows the similarity of the two models for a flat plate boundary layer.

Near wall damping model. In the Baldwin-Lomax model $A^{+}=26$, while in both the Kays and Moffat ${ }^{(20)}$ and the Cebeci-Smith ${ }^{(21)}$ turbulent boundary layer models $\mathrm{A}^{+}$is a function of the freestream pressure gradient, $P^{+}$. The Kays and Moffatt model gives:

$$
A^{+}=25 /\left(C_{\mathrm{KM}} P^{+}+1\right)
$$

$C_{\mathrm{KM}}=30.2$ for $P^{+} \leq 0.0$, otherwise $C_{\mathrm{KM}}=20.6$. The Cebeci-Smith model gives:

$$
A^{+}=26 / \sqrt{\left(11.8 P^{+}+1\right)}
$$

Figure 3 gives the damping coefficient as a function of the pressure gradient for the three models. The greatest differences among the models occur for favorable pressure gradients. When $A^{+} \rightarrow \infty$, the boundary layer completely relaminarizes. The Kays and Moffatt model shows complete relaminarization occuring at lower favorable pressure gradients than the CebeciSmith model.

Crawford and Kays ${ }^{(1)}$ recommend that a lag equation be used for the pressure gradient value used to determine the damping coefficient. They recommend the form suggested by Jones and Launder ${ }^{(22)}$.

$$
d P^{+} / d s^{+}=-\left(P^{+}-P_{\mathrm{eq}}^{+}\right) / C
$$

Here $P_{\text {eq }}^{+}$is equilibrium value for the pressure gradient, and $C$ has a recommended value of 4000 . The streamwise distance between nodes in a Navier-Stokes analysis is much greater than the marching distance used in a boundary layer analysis. This can result in large pointto-point variations in the pressure gradient. The lag equation smooths out these variations, and was always used when $A^{+}$was allowed to vary.

Freestream turbulence model. The strong favorable freestream pressure gradients near the leading edge results in laminar flow, even with high freestream turbulence. The freestream turbulence increases the laminar heat transfer. The model of Smith and Kuethe ${ }^{(23)}$ was incorporated into the analysis to account for this effect. The equation for the turbulent viscosity is:

$$
\epsilon_{M}=0.164 y T u_{\infty} U_{\infty}
$$

This equation was developed for the heat transfer analysis of cylinders in crossflow, and here $U_{\infty}$ refers to the upstream velocity. One difficulty with applying this model in a computational scheme is that the eddy viscosity continually increases with the distance from the blade. The model of Forrest ${ }^{(24)}$ can be used to overcome this difficulty. This model gives:

$$
\epsilon_{M}=C_{F} \ell T u_{\infty} U_{\infty}
$$

where the mixing length, $\ell$, is defined as

$$
\ell=\min (\kappa y, 0.086 \delta)
$$

Since one of the attractive features of the BaldwinLomax turbulence model is that boundary layer parameters are not calculated, the model of Forrest was implemented by calculating the mixing length, $\ell$ in the same manner as in the Baldwin-Lomax model. This was done 
by letting $\ell=\kappa y$ when the Baldwin-Lomax eddy viscosity was calculated from the inner formulation. When the outer formulation was used, the mixing length in Forrest's model was either held constant at the crossover value or set to zero. The coefficient $C_{F}$ is found from:

$$
C_{F}=\min (0.1875|\lambda| /(0.25|\lambda|+0.01), 0.75)
$$

where

$$
\lambda=\frac{\theta^{2}}{\nu} \frac{d U_{e}}{d s}
$$

The calculation of $\epsilon_{M}$ due to freestream turbulence was modified from the original form in that it was applied only when the flow was laminar. Otherwise, the analysis would give significantly increased heat transfer due to freestream turbulence even for fully turbulent flow.

The momentum thickness is not calculated directly. Rather, Twaites' method, as given by White ${ }^{(19)}$, is used. The momentum thickness at a distance $s_{1}$ along the blade surface is given by:

$$
\theta^{2}\left(s_{1}\right)=\frac{0.45 \nu}{U_{e}^{6}\left(s_{1}\right)} \int_{0}^{s_{1}} U_{e}^{5} d s
$$

The origin in this calculation is taken as the geometric stagnation point.

Transition model. In the Baldwin-Lomax model transition occurs when the pressure gradient does not effect transition, except insofar as it affects the vorticity. Perhaps more importantly, the effect of freestream turbulence is also not accounted for. The choice of transition models to be included in the calculation procedure was limited to those which explicitly accounted for the effects of both freestream turbulence and pressure gradient. The model of Dunham ${ }^{(25)}$ was chosen. This model gives the start of transition $R e_{\theta i}$ as :

$$
R e_{\theta i}=\left(0.27+0.73 e^{-80 T u}\right)(550+680 /(1-D))
$$

with $D$ given as a function of the pressure gradient parameter $\lambda$ :

$$
D=\min (21 \lambda-100 T u, 0.75)
$$

Where $\lambda$ is given by equation 19. Comparisons for a range of $\lambda$ and $T u$ values showed Dunham's model to give lower $R e_{\theta i}$ values than the model of Seyb ${ }^{(26)}$. Dunham's model gave nearly the same values when compared with the model of Abu-Ghannam and Shaw ${ }^{(27)}$. Dunham's model was chosen for implementation over the other models because the pressure gradient enters in a linear fashion, and is less likely to result in oscillations in the transition location as the calculations progress.

Even the approximate calculation of the momentum thicknesses can cause difficulties, especially near the stagnation point. The edge velocity, $U_{e}$, is calculated from the local static and freestream total pressures. If stagnation occurs other than at the geometric stagnation point, $U_{e}$ will $\rightarrow 0$ and $\theta$ will $\rightarrow \infty$. Consequently, transition would occur at this point. To prevent this, transition was not allowed to occur within a small fraction, (about 10\%), of the the surface distance from the stagnation point.

Transition length is determ ned from Dhawan and Narashima ${ }^{(28)}$ model. The end cf transition is given by:

$$
R e_{\mathrm{Si}}=R e_{\mathrm{Si}}+c R e_{\mathrm{Si}}{ }^{8}
$$

The coefficient, $c$, has a value of 5.0 for a transition length between $25 \%$ and $75 \%$ intermittency. For the full intermittency range between 0 and $99 \%$, the coefficient, $c$, increases by a factor of 3.36. The intermittency factor $\gamma_{t}$ of Abu-Ghannam and Shaw ${ }^{(27)}$ is used:

$$
\gamma_{t}=1-e^{-4.65\left(\left(R e_{\mathrm{s}}-R e_{s_{i}}\right) /\left(R e_{\mathrm{si}_{\mathrm{f}}}-R e_{\mathrm{s}_{1}}\right)\right)^{3}}
$$

\section{CALCULATION PROCEDURE}

The GRAPE code of Sorenson ${ }^{(28)}$ was used to generate $\mathrm{C}$-grids for the analysis. The locations of the intersection of grid lines with the inner and outer boundaries was controlled to give minimum shear in regions of interest. For example, it was often desired to have near normal grids on the rearward portion of the suction surface. However, because of the large amount of turning, a near-normal grid could not be generated over the entire blade surface and still maintain grid-line periodicity on the outer boundary. Fortunately, the presence of sheared grid lines did not appear to adversely affect the flow solutions.

The thick trailing edges made it necessary to use trailing edge cusps. Without a cusp, there was a large loss in total pressure in the trailing edge region, even for the inviscid calculations. Inviscid calculations were used to determine the shape of the cusp. The cusp shape was adjusted to give no net loading over the cusp region beyond the physical end of the turbine blade.

After the Euler solution was obtained, the NavierStokes solution was calculated for the same blade geometry, but with a $y^{+} \approx 1$ for the first node from the wall. For the Euler calculation the first node spacing wall increased about an order of magnitude to avoid an unacceptably large total pressure loss.

Steady state was reached in 3000 to 5000 time cycles. Residuals were reduced at least two orders of magnitude. Figure 4 shows the convergence history as well as pressure distributions and heat transfer results for a typical case. Reductions in residuals by two orders of magnitude were needed for converged heat transfer results, but fewer cycles were needed for pressure.

Figure 5 shows converged results for three different grids. Grids of $145 \mathrm{X} 46,284 \mathrm{X} 46$, and $145 \mathrm{X} 31$ were 
used. The coarser grid in the $\xi$ direction, $145 \mathrm{X} 46$, gave satisfactory agreement with the finer grid, $284 \times 46$, in this direction. However, the results were sensitive to the number of grid lines in the $\eta$ direction. The number of grid lines in the $\xi$ direction was determined by the desire to resolve the surface pressure distribution. When strong surface pressure gradients were encountered, a large number of $\xi$ grid lines were used.

Figure 6 shows heat transfer results as a function of the distance of the first node from the wall, $y_{1}^{+}$, expressed in terms of $y_{\mathrm{REF}}^{+}$. This value is calculated prior to the viscous calculation, where $y_{\mathrm{REF}}^{+}=$ $\left(y_{1} U_{e} / \nu\right) \sqrt{C_{f} / 2}$. The value of $C_{f}$ is obtained from a flat plate correlation: $C_{f} / 2=0.0287\left(s U_{e} / \nu\right)^{-0.2}$, to give:

$$
y_{\mathrm{REF}}^{+}=0.17 y_{1} R e^{0.9} / s^{0.1}
$$

The largest value of the unit Reynolds number, typically the one based on exit conditions, gives the largest value for $y_{R E F}^{+}$. This, in turn, gives a conservative estimate of $y_{1}^{+} \cdot y_{R E F}^{+}$is only slightly affected by the choice of $s$, and $s$ can be taken as the chord. When $s \rightarrow 0$, near the stagnation point, so does $U_{e}$, and $y_{\mathrm{REF}}^{+}$remains finite. Figure 6 shows that $y_{1}^{+}$values approximately equal to one are sufficient. Since $y^{+}$is related to the normalized temperature by the Prandtl number, sensitivity to $y^{+}$ reflects the sensitivity to normalized temperature.

The Navier-Stokes and Euler solutions took approximately 250 and 200 seconds on a Cray X-MP for 3000 time cycles using a 145 by 46 grid.

Predictions were made with a specified wall temperature approximately equal to the average of the experimental wall temperatures. Varying the wall temperature showed no change in the heat transfer as long as the analytic gas-to-wall temperature difference was equal to or greater than the experimental one. It was felt that it was appropriate to compare heat transfer calculated assuming constant wall temperature with experimental data generated from nominally constant heat flux conditions. In the experiments there was some lateral conduction within the blade surface, whi h changes the boundary condition from one of constant flux to one with more slowly varying temperature. If calculations are made using specified wall flux, comparisons of heat transfer coefficients may not adequately verify a code's ability to predict heat transfer. If the Reynolds number is sufficiently high, and the specified heat flux sufficiently low, the gas temperatures adjacent to the wall will not significantly change from the no heat flux case. Under these conditions, comparisons of heat transfer coefficients will show good agreement, independent of how far the first grid point is from the wall.

The temperature gradient at the wall accounted for the non-orthonality of the grid lines, and was evaluated using a three point formula:

$$
\frac{\partial T}{\partial y}=\frac{\xi_{m} \eta_{\theta} / r-\eta_{m} \xi_{\theta} / r}{\sqrt{\eta_{m}^{2}+\left(\eta_{\theta} / r\right)^{2}}} \frac{\left(-3 T_{1}+4 T_{2}-T_{3}\right)}{2}
$$

\section{COMPARISONS with DATA}

In the comparisons that follow, a prediction which gave good agreement for a number of cases is given by the solid curve. This model incorporates Dunham's transition model, and the Smith and Kuethe freestream turbulence augmentation effect. In addition to this curve, other curves are shown in each figure to illustrate the effects of various parameters on blade heat transfer. A further discussion of the appropriate heat transfer model will occur after the results for all of the comparisons have been presented. Conclusions based on one set of data may not be appropriate for another set, and the appropriate model is a best fit model to all of the data.

\section{Stator results}

Low speed cascade tests. Figure 7 compares predicted and experimental results for the stator of Dring et al. Figure 7 a shows reasonably good agreement between the analysis and the experimental pressure distribution. The pressures are slightly higher on the rearward portion of the suction surface. The pressure gradient, though, is accurately predicted. The pressure gradient is more important than the small differences in levels in predicting the heat transfer.

Figure $7 \mathrm{~b}$ shows heat transfer comparisons at design Reynolds number, and low freestream turbulence. The transition model is very sensitive to the freestream turbulence at low turbulence intensities. This can be seen by comparing the prediction at a turbulence level of $1.5 \%$ with the prediction of no freestream turbulence. The Baldwin-Lomax transition model gave a reasonably accurate prediction of suction surface transition for this case. It was observed that this model predicted transition when the suction surface pressure gradient became positive, and was somewhat accurate only when the freestream turbulence level was low.

Figure 7c shows the effect of a variation in the freestream turbulence on the transition location for the same Reynolds number as in figure $7 \mathrm{~b}$, but at higher freestream turbulence. One curve assumes $T u=T u_{\infty}$, and the other assumes $T u=T u_{\infty} U_{\infty} / U_{e}$. Since the suction surface pressure is near a minimum at transition, the second assumption results in transition occuring further back on the suction surface. Dunham sugested that the turbulence intensity be taken as the average of two values, which are closely approximated by these two values. Consequently, these two curves reprent the range of turbulence intensities for use in the transition model. Also shown in this figure is a fully turbulent prediction.

Stanton numbers at an intermediate Reynolds number for two $T u_{\infty}$ values are shown in parts $d$ and e. Figure $7 \mathrm{~d}$ shows that the shorter transition length agrees better with the rapid rise in heat transfer. Part e shows the effect of a variable $P r_{t}$ to be relatively small, even 
though figure 1 shows $\boldsymbol{P r}_{t}$ to be twice as large at the wall for the variable $P_{r_{t}}$ assumption. Part $f$ shows that the effects of both Deissler's near wall turbulence model and the Cebeci-Smith relaminarization model are also relatively small for the lowest Reynolds number with an upstream turbulence grid.

Transonic cascade tests. Figure 8 gives comparisons for the Mark II stator of Hylton et al. Figure $8 \mathrm{a}$ shows that because of the rapid rise in suction surface pressure near midchord, a grid with 271 circumferential lines was needed to accurately predict surface pressures. Due to the large adverse suction surface pressure gradient the flow separated, and boundary layer analyses could not be used downstream of the separation. Figure $8 \mathrm{~b}$ shows heat transfer comparisons for the two grid densities and for a case where the measured wall temperatures were used for the boundary conditions. This case, which used the $271 \times 53$ grid, shows that the variation in wall temperature did not account for the overshoot in predicted heat transfer. Even though the overshoot was large, it was very narrow. It appears that the thermal modeling is incorrect immediately after separation, or perhaps, there was some smoothing of the experimental data due to conduction. The $146 \times 53$ grid gives results in better agreement with the heat transfer data, though not with the surface pressure data.

Figure 8c shows that Baldwin-Lomax transition criterion is less satisfactory than Dunham's model for pressure surface transition using the $146 \times 53$ grid. Figure $8 \mathrm{~d}$ shows that neglecting the effect of freestream turbulence at $T u=8.3 \%$ underpredicts the heat transfer in the leading edge region. Figure $8 \mathrm{e}$ shows that using a variable $\operatorname{Pr}_{t}$ increased the predicted heat transfer slightly, and did not agree better with the data for either pressure or suction surfaces. Figures $8 b$ through $8 \mathrm{e}$ show reasonably good agreement between the predicted and experimental suction surface heat transfer downstream of separation. This shows the usefulness of the Navier-Stokes approach for turbine blade heat transfer.

Comparisons are shown in figure 9 for similar conditions as shown in figure 8 for the Mark II stator. Figure 9a shows good agreement in surface pressures for the C3X stator of Hylton et al. There is no indication of separation for the higher solidity C3X stator. Figure $9 \mathrm{~b}$ shows an accurate heat transfer prediction for the case with low $R e$ and pressure ratio of 0.582 , except on the rear portion of the pressure surface. This figure also shows that the effects of Deissler's near wall turbulence model is relatively small. A prediction with $T u_{\infty}$ reduced to $5 \%$ is also shown, and is in somewhat better agreement with the data. This is shown because the turbulence may have decayed somewhat between the measuring station and the leading edge of the blade. Figure $9 c$ gives comparisons at high $R e$, where freestream turbulence effects on heat transfer are expected to be large. Forrest's model for freestream turbulence effects is very close to the data in the leading edge region. This model agrees with the data better than the Smith and Kuethe model. Calculations with Forrest's model showed only small changes in heat transfer when the turbulent viscosity was calculated with a mixing length limited to the crossover value, or even neglected in the outer region.

Figure 9d shows good agreement with the heat transfer data at the low $R e$ and pressure ratio of 0.490 . The figure also shows that the $A^{+}$model had little effect on the heat transfer. Figure $9 \mathrm{e}$ shows a fully turbulent calculation to agree better with the data than a model with transition for the high $R e$ and low pressure ratio case. The improved agreement occurs in the leading edge region, and just prior to suction surface transition.

Linear cascade tests. Figure 10a compares surface pressures for the vane data of Hippensteele et al. Figure $10 \mathrm{~b}$ compares heat transfer results at design Reynolds number and low turbulence intensity for two transition lengths and for the Baldwin-Lomax transition criteria. In contrast to figure $7 \mathrm{~d}$, the longer transition length agrees better with the data. However, either transition length in Dunham's model agrees better than the Baldwin-Lomax criterion. Figure 10c shows that the freestream turbulence model of Forrest agrees with the heat transfer data better than the model of Smith and Kuethe at high $T u$. Figures 10d shows a longer transition length than the data for the low $R e$ - low $T u$ case. Since even the suction surface transitioned near the rear of the vane, any turbulence generated within the passage would move transition forward. Increasing $T u$ to $3 \%$ in the prediction gave the correct suction surface transition. Figure 10e shows that, even with high $T u$, suction surface transition is delayed to the near midchord as a result of the low Reynolds number.

\section{Rotor results}

Large scale rotor. Figure 11 compares pressure distributions and heat transfer results for three different values of flow coefficient, $\phi$. Changing $\phi$ changes the inlet flow angle. There is good agreement in pressure distributions between the analysis and data for all three $\phi$ values. Changing inlet flow angle gives different pressure distributions, with different boundary layer growth rates, which in turn affect the blade heat transfer. When $\phi=0.68$, the flow is more tangential, resulting in a greater adverse pressure gradient along the pressure surface. When $\phi=0.96$, the flow angle is reduced from the design case. This in turn gives a less favorable gradient along the suction surface.

Heat transfer comparisons are shown for three $\phi$ values at design Reynolds number, and for $\phi=0.78$ at a low $R e$. Since the test occurred in a rotating rig, the rotor, being behind the stator, was always in a high turbulence environment. The effect of augmenting the viscosity to account for freestream turbulence is shown in figure $11 \mathrm{~b}$. Figure $11 \mathrm{~d}$ shows that a constant value of $\mathrm{A}^{+}$ 
gives the best prediction on the suction surface. It was observed that for high $T u$ cases neglecting relaminarization often gave the best agreement with the data for the pressure surface. Since high freestream turbulence causes laminar boundary layers to become turbulent, it may also inhibit relaminarization of turbulent boundary layers. Figure $11 \mathrm{f}$ shows that a fully turbulent boundary layer calculation gives a reasonably accurate prediction for the entire blade surface. However, because this model does not account for the level of freestream turbulence, the leading edge region heat transfer may in some cases be in error. The heat transfer prediction for the low Reynolds number case in figure $11 \mathrm{~g}$ is accurate, except for the prediction of transition. The underprediction of pressure surface heat transfer again suggests that relaminarization is not appropriate in a high $T u$ environment.

Large scale exit vane. The exit vane of the tests of Dring et al. had a shape similar to the rotor. Therefore, comparisons for this blade row are included with other rotor results. Figure 12 compares surface pressure and heat transfer predictions. The analysis underpredicts the heat transfer even for the turbulent assumption on the rearward portion of the suction surface. While only one prediction is shown in figure 12, several other cases were run with other assumptions for $\operatorname{Pr}_{t}, A^{+}$, and the near wall damping model. No case gave heat transfer results that agreed with the data on the rear portion of the suction surface. It appears that the thermal modeling is in error, or perhaps there are three-dimensional flow effects. The fully turbulent boundary layer prediction shown by Dring et al. also underpredicted this heat transfer.

Linear cascade rotor. The rotor tested by Hippensteele, Russell, and Torres showed pressure surface separation. Figure 13a gives comparisons of surface pressures. While there is good reasonably good agreement between the analysis and experimental surface pressures, the analysis shows a more stronger suction surface adverse pressure gradient than might be inferred from the data.

The tests were done in a low freestream turbulence environment. Consequently, transition occurred towards the rear of the blade on the suction surface. Figure $13 \mathrm{~b}$ shows an early prediction of suction surface transition at the highest Reynolds number. This was probably the result of an overly strong suction surface adverse pressure gradient. At the lower Reynolds numbers, figures $13 \mathrm{~b}$ and $\mathrm{c}, R e_{\theta}$ was not large enough to initiate transition at this point on the blade. This figure shows only a small effect on suction surface transition when the freestream turbulence is assumed to vary with the local freestream velocity,

On the pressure surface separation occurred near the leading edge. At all Reynolds numbers the pressure surface heat transfer reached a second peak as a result of separation. Because this occurred close to the leading edge, $\theta$, calculated from equation 20, was too small to initiate transition in this region. Best agreement with the pressure surface data was achieved when the Navier-Stokes analysis was used to indicate transition. Once a negative wall friction was calculated, the flow was assumed to be fully turbulent. This assumption gave the location of a transition like increase in heat transfer only slightly downstream of separation. The higher heat transfer along most of the pressure surface compared with the suction surface was predicted. The analysis predicted an increase in heat transfer at separation. The increase was from a lower laminar level, and, in contrast to the experimental data, the heat transfer did not reach the leading edge level. The results in figure 8 showed that a denser grid changed the heat transfer predictions at separation. For the rotor case, however, the heat transfer did not change with a denser grid.

\section{Choice of Heat Transfer Morlel}

The results in figures 7 through 13 siow that the choice of heat transfer model is somewhat dependent on the flow field environment. When both the Reynolds number and $T u$ are high, a fully turbulent model gives accurate predictions. When the Reynolds number is low, even if $T u$ is high, transition must be accounted for. Dunham's transition model gives accurate predictions, and the actual level of freestream turbulence, even if it is low, should be used. When the turbulence level is low, but not known, a value of at least $2 \%$ should be used. When the turbulence level is low, and especially if the Reynolds number is also low, a negative skin friction should be used to switch to fully turbulent flow. This should not be done in the immediate region of tl e stagnation point so as to avoid spurious transition. At stagnation the sign of the shear stress is indeterminate. The transition criterion in the Baldwin-Lomax model is less accurate, principally because it fails to account for freestream turbulence. The data comparisons did not indicate a strong preference for either the 0 to $99 \%$ intermittency model or the $25 \%$ and $75 \%$ one. Both gave reasonably accurate results.

The choice of relaminarization model also was dependent on the freestream turbulence environment. With high $T u$ it did not appear appropriate to increase $\mathrm{A}^{+}$when the pressure gradient was strongly favorable. Since high freestream turbulence causes a laminar boundary to become turbulent, it also may inhibit relaminarization of a turbulent bounary layer. Otherwise the Kays and Moffat model appeared slightly favorable, perhaps only from a computational standpoint, to the Cebeci-Smith model.

Not only did Deissler's near wall turbulence model give similar results to the widely used VanDriest model for a flat plate boundary layer, the results were nearly the same for the heat transfer after separation occurred. 
Using a variation in $\mathrm{Pr}_{t}$ instead of a constant value did not result in significantly different heat transfer results. However, there was some indication that at low Reynolds numbers a variable $P r_{t}$ would give higher heat transfer rates.

The model of Forrest for the heat transfer augmentation in laminar flow was in better agreement with the data. If the model of Smith and Kuethe is used, best agreement with the data is achieved when the coefficient used in their model is reduced by about $50 \%$. A reduction of this magnitude is consistent with the observations made by O'Brien and VanFossen ${ }^{(30)}$.

\section{CONCLUSIONS}

Comparisons with experimental data showed good agreement in terms of surface pressures for the several different turbine blades. When the surface pressure changed abruptly, grids of high density were required. Otherwise, a grid size of $145 \times 46$ was adequate.

Reductions in residuals of at least two orders of magnitude were required in order to achieve converged heat transfer predictions. Convergence was slower for the pressure surface heat transfer than for the suction surface heat transfer. Use of the GRAPE code to generate grids proved satisfactory.

The ability of the thin-layer Navier-Stokes analysis to accurately predict turbine blade heat transfer downstream of separations demonstrates the utility of this approach. After separation, a fully turbulent prediction agrees well with the data. The degree of agreement between the analysis and the experimental data is primarily determined by the choice of model for transition. The Navier-Stokes results should be used to change the calculation procedure from laminar to turbulent when separation is indicated.

\section{REFERENCES}

1. Crawford, M.E., and Kays, W.M. "STAN5A Program for Numerical Computation of TwoDimensional Internal and External Boundary Layer Flows", NASA CR 2742, 1976.

2. Chima, R.V., "Development of an Explicit Multigrid Algorithm for Quasi-Three- Dimensional Viscous Flows in Turbomachinery," AIAA paper 86-0032, 1986 (NASA TM-87128)

3. Chima, R.V., and Yokota, J.W., "Numerical Analysis of Three-Dimensional Viscous Internal Flows," AIAA paper 88-3522, 1988 (NASA TM-100878)

4. Davis, R.L., Hobbs, D.E., and Weingold, H.D, "Prediction of Compressor Cascade Performance Using

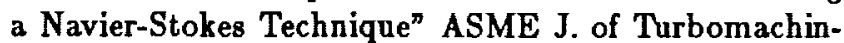
ery, Vol. 110, No.4, Oct. 1988, pp. 520-531.

5. Hah, C., "Numerical Study of Three-Dimen- sional Flow and Heat Transfer Near the Endwall of a Turbine Blade Row," AIAA paper 89-1689, 1989.

6. Yang, R.J., Weinberg, B.C., Shamroth, S.J., and McDonald, H., "Turbine Vane External Heat Transfer - Vol. II Numerical Solutions of the Navier-Stokes Equations for Two and Three-Dimensional Turbine Cascades with Heat Transfer", NASA CR174828, 1985.

7. Chima, R.V., Turkel, E., and Schaffer, S., "Comparison of Three Explicit Multigrid Methods for the Euler and Navier-Stokes Equations", AIAA paper 87-0602, 1987 (NA i A TM-88878)

8. Baldwin, B.S., and Lomax, H. “Thin-Layer Approximation and Algebraic Model for Separated Turbulent Flows," AIAA Paper 78-257, Jan. 1978.

9. Deissler, R.G., "Analysis of Turbulent Heat Transfer, Mass Transfer, and Friction in Smooth Tubes at High Prandtl and Schmidt Numbers," NACA Report $1210,1955$.

10. Dring, R.P., Blair, M.F., Joslyn, H.D., Power, G.D., and Verdon, J.M., "The Effects of Inlet Turbulence and Rotor/Stator Interactions on the Aerodynamics and Heat Transfer of a Large-Scale Rotating Turbine Model. Pt I - Final Report," NASA CR 4079, 1986.

11. Dring, R.P., Blair, M.F., and Joslyn, H.D., "The Effects of Inlet Turbulence and Rotor/Stator Interactions on the Aerodynamics and Heat Transfer of a Large-Scale Rotating Turbine Model. Pt. II - Heat Transfer Data Tabulation-15\% Axial Spacing," NASA CR 179467, 1986.

12. Dring, R.P., Blair, M.F, and Joslyn, H.D., "The Effects of Inlet Turbulence and Rotor/Stator Interactions on the Aerodynamics and Heat Transfer of a Large-Scale Rotating Turbine Model. Pt. III - Heat Transfer Data Tabulation-65\% Axial Spacing," NASA CR 179468, 1986.

13. Dring, R.P., Joslyn, H.D., and Blair, M.F., "The Effects of Inlet Turbulence and Rotor/ Stator Interactions on the Aerodynamics and Heat Transfer of a Large-Scale Rotating Turbine Model. Pt. IV - Aerodynamic Data Tabulation," NASA CR 179469, 1986.

14. Hylton, L.D., Mihelc, M.S., Turner, E.R., Nealy, D.A., and York, R.E., "Analytical and Experimental Evaluation of the Heat Transfer Distribution Over the Surfaces of Turbine Vanes," NASA CR 168015, 1983.

15. Hippensteele, S.A., Russell, L.M., and Torres, F.J., "Use of a Liquid-Crystal, Heater-Element Composite for Quantitative, High-Resolution Heat Transfer Coefficients on a Turbine Airfoil, Including Turbulence and Surface Roughness Effects, ${ }^{n}$ in: Pressure and Temperature Measurements, J.H. Kim and R.J. Moffat eds. ASME FED-Vol. 44/HTD-Vol. 58, pp.105-120, 1986. (NASA TM-87355)

16. Hippensteele, S.A., Russell, L.M., and Torres, F.J., “Local Heat-Transfer Measurements on a Large Scale-Model Turbine Blade Airfoil Using a Composite of 
a Heater Element and Liquid Crystals", J. of Engr. for Gas Turbines and Power, Vol 107, 1985, pp 953-960.

17. Katsanis, T. and McNally, W.D., "Revised FORTRAN Program for Calculating Velocities and Streamlines on the Hub-Shroud Midchannel Stream Surface of an Axial-, Radial, or Mixed-Flow Turbomachine or Annular Duct, Vol. I - User's Manual," NASA TN D-8430, 1977.

18. Pai, B.R., and Whitelaw, J.H., "The Prediction of Wall Temperature in the Presence of Film Cooling," Int. J. Heat \& Mass Transfer, Vol 14, 1971, pp 409-426.

19. White, F.M., "Viscous Fluid Flow," McGrawHill, Inc, New York, 1974.

20. Kays, W.M., and Moffat, R.J., "The Behavior of Transpired Boundary Layers," in Studies in Convection, Vol. 1: Theory, Measurement, and Application, B.E. Launder ed. Academic, London, 1975.

21. Cebeci, T., and Smith A.M.O., "Analysis of Turbulent Boundary Layers," Academic, New York, 1974.

22. Jones, W.P., and Launder, B.E., "On the Prediction of Laminarescent Turbulent Boundary Layers," ASME paper 69-HT-13, 1969.

23. Smith, M.C., and Kuethe, A.M., "Effects of Turbulence on Laminar Skin Friction and Heat Transfer," Physics of Fluids, Vol 9, 1966, pp 2337-2344.

24. Forrest, A.E., "Engineering Predictions of Transitional Boundary Layers," AGARD-CP- 224, 1977.

25. Dunham, J., "Predictions of Boundary Layer Transition on Turbomachinery Blades," AGARD-AG164, 1972.

26. Seyb, N.J., "The Role of Boundary Layers in Axial Flow Turbomachines and the Prediction of Their Effects," AGARD-CP-224, 1977.

27. Abu-Ghannam, B.J., and Shaw, R., "Natural Transition of Boundary Layers- The Effects of Turbulence, Pressure Gradients, and Flow History," J. of Mech. Engr. Science, Vol 22, No. 5, 1980, pp 213-228.

28. Dhawan, S., and Narashima, R., "Some Properties of Boundary Layer Flow During Transition from Laminar to Turbulent Motion," J. of Fluid Mechanics, Vol. 3, 1958, pp 418-436.

29. Sorenson, R.L., "A Computer Program to Generate Two-Dimensional Grids About Airfoils and Other Shapes by the Use of Poisson's Equation," NASA TM81198, 1980.

30. O'Brien, J.E., and VanFossen, G. J., "The Influence of Jet-Grid Turbulence on Heat Transfer from the Stagnation Region of a Cylinder in Crossflow," ASME paper 85-HT-58, 1985. 


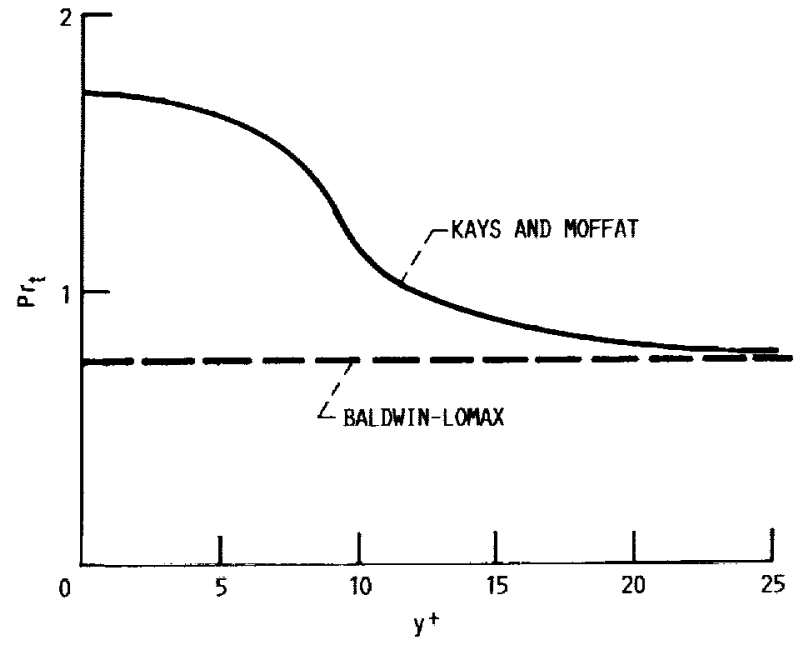

FIGURE 1. - VARIATION OF TURBULENT PRANDTL NUMBER WITH DISTANCE FROM THE WALL FOR FLOW OVER A FLAT PLATE.

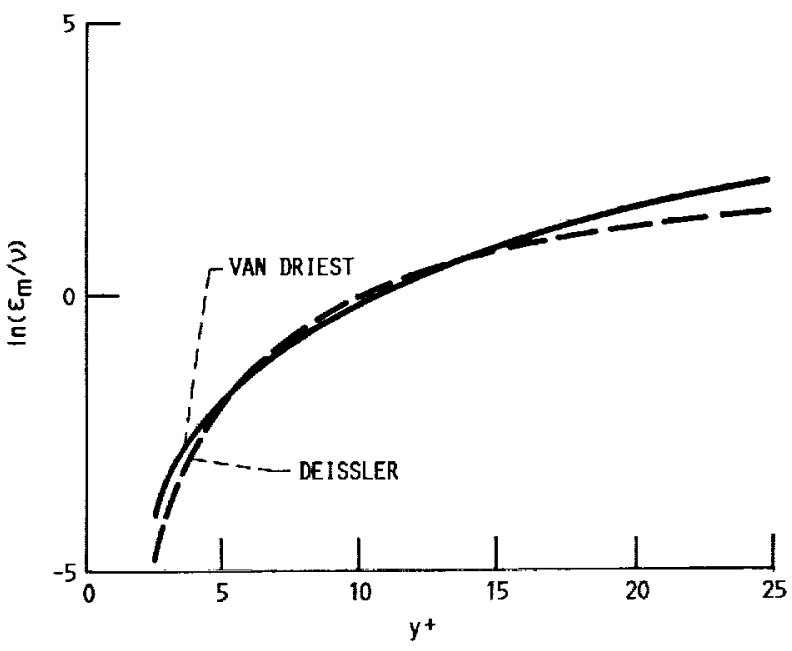

FIGURE 2. - COMPARISON OF VAN DRIEST AND DEISSLER EDDY VISCOSITY MODEL IN NEAR WALL REGION.

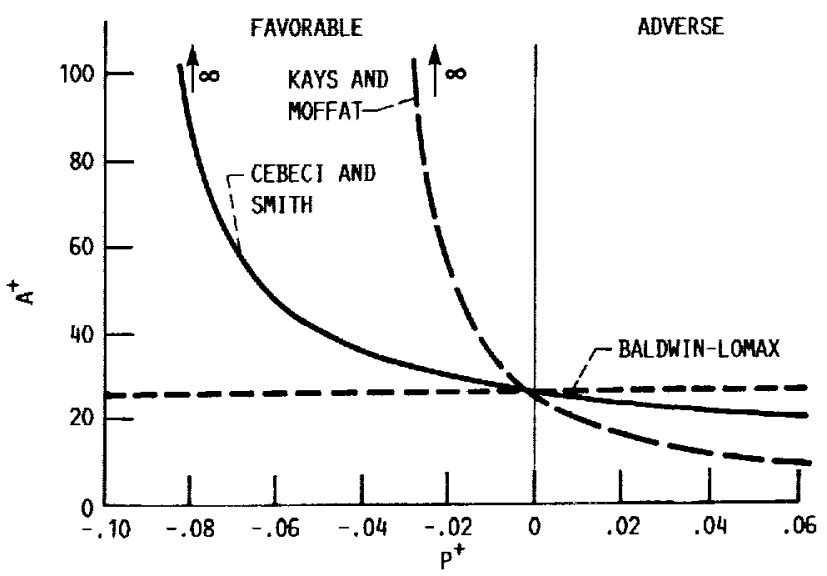

FIGURE 3. - COMPARISON OF KAYS AND MOFFAT, CEBECI-SMITH. AND BALDWIN-LOMAX DAMPING COEFFICIENTS MODELS AS A FUNCTION OF PRESSURE GRADIENT.

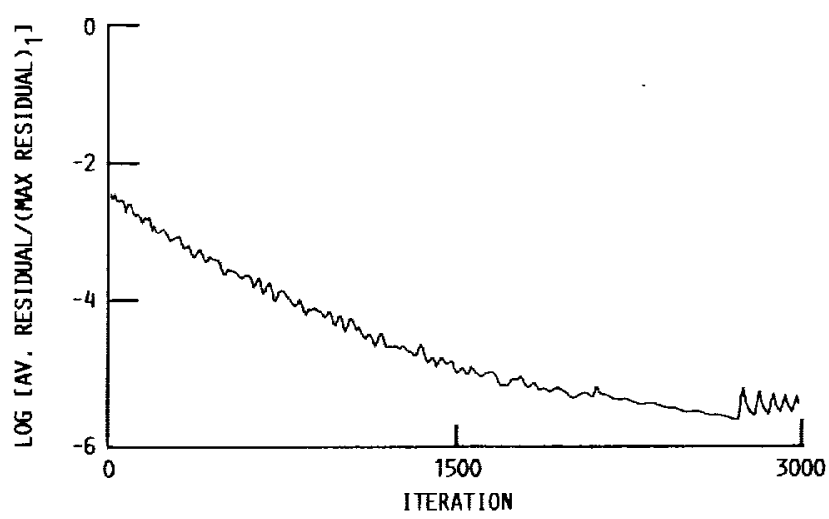

(a) RESIDUALS.

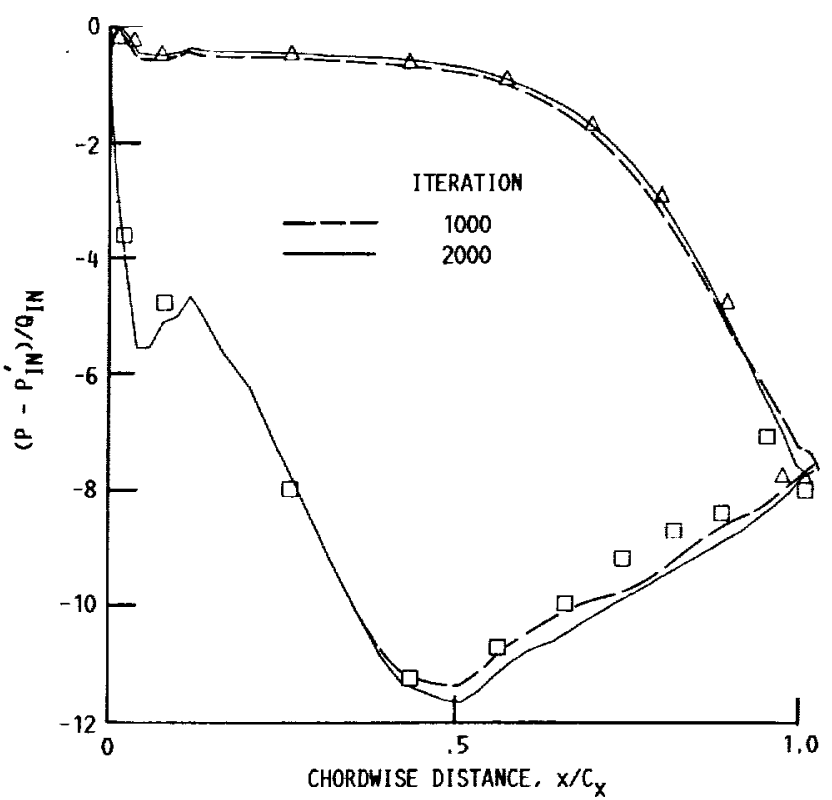

(b) SURFACE PRESSURES.

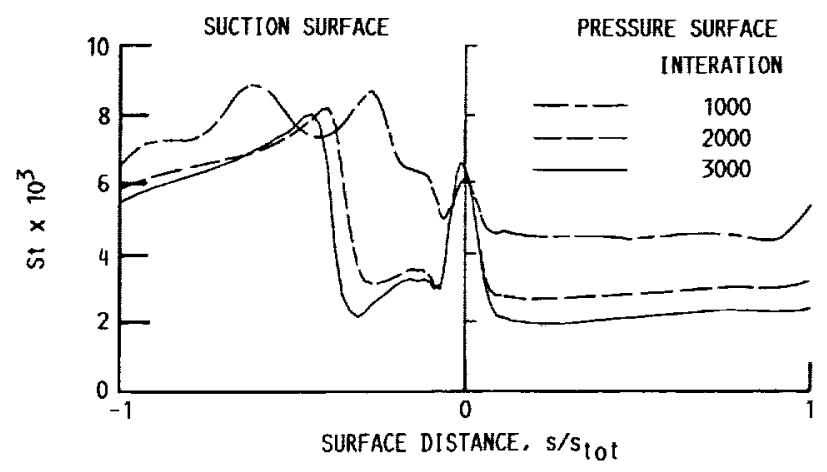

(C) STANTON NUMBER,

FIGURE 4. - CONVERGENCE HISTORY FOR A SAMPLE CASE. 


\section{ORIGINAL PAGE IS OF POOR QUALITY.}

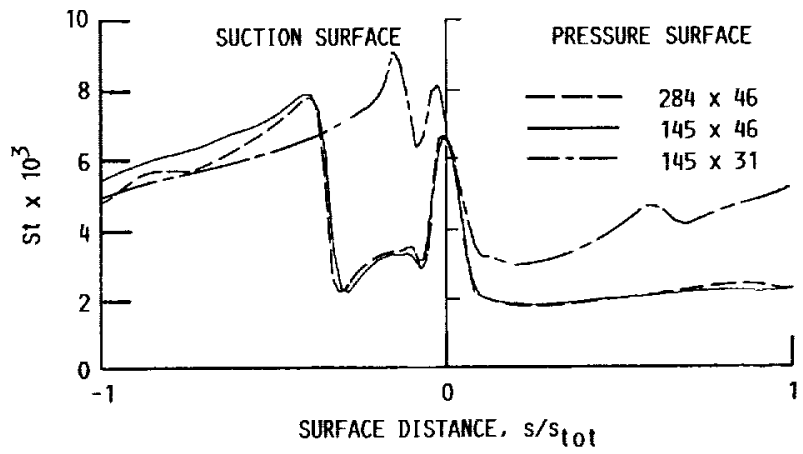

FIGURE 5. - COMPARISON OF STANTON NUMBER DISTRIBUTION FOR DIFFERENT GRIDS.

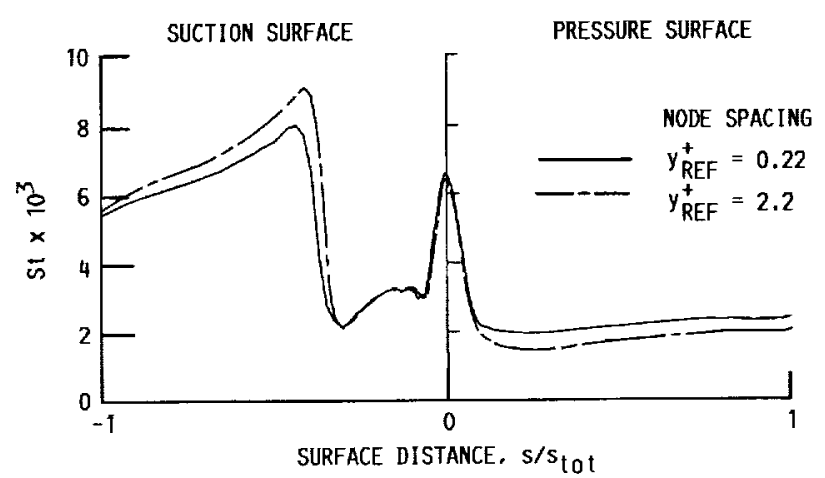

FIGURE 6. - EFFECT OF FIRST NODE SPACING ON SURFACE HEAT TRANSFER. 


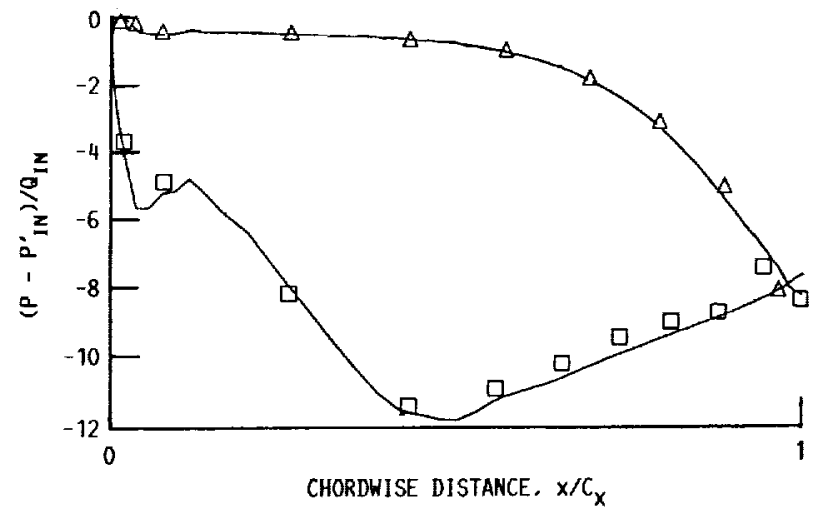

(a) SURFACE PRESSURES.

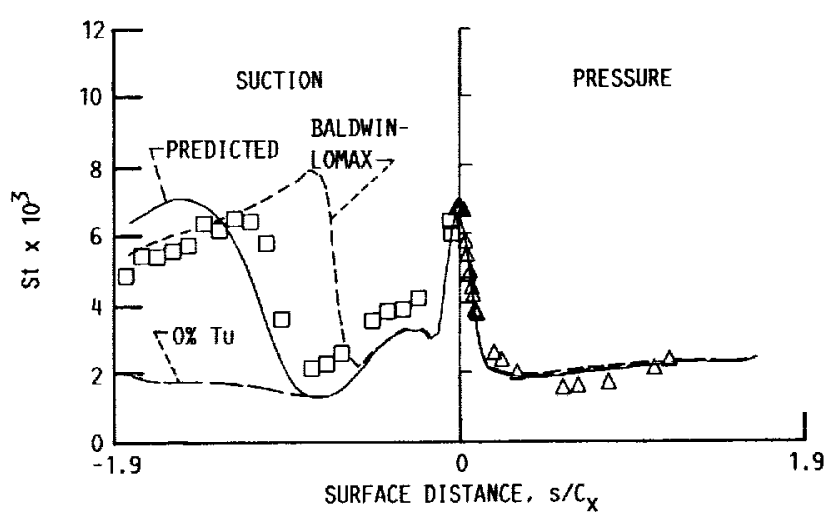

(b) STANTON NUMBER AT DESIGN Re. NO TURBULENCE GRID.

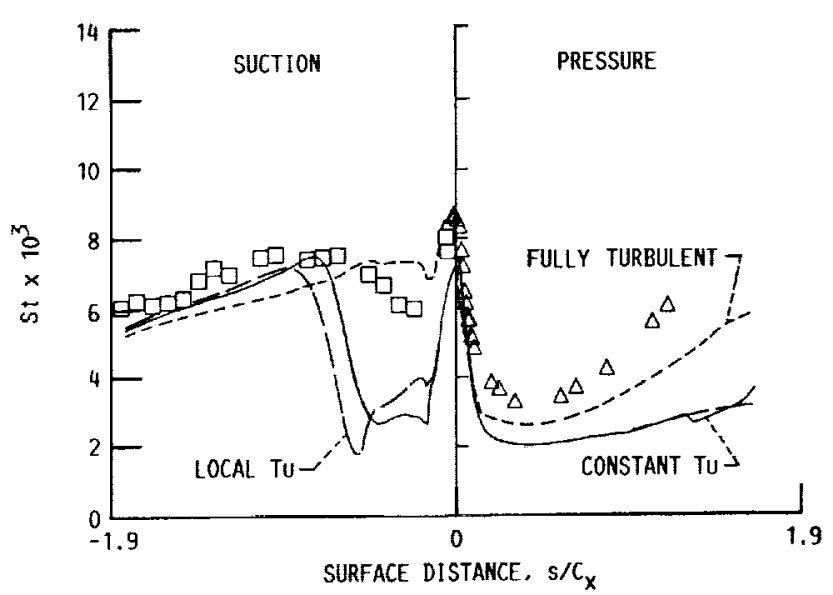

(C) STANTON NUMBER AT DESIGN Re, TURBULENCE GRID.

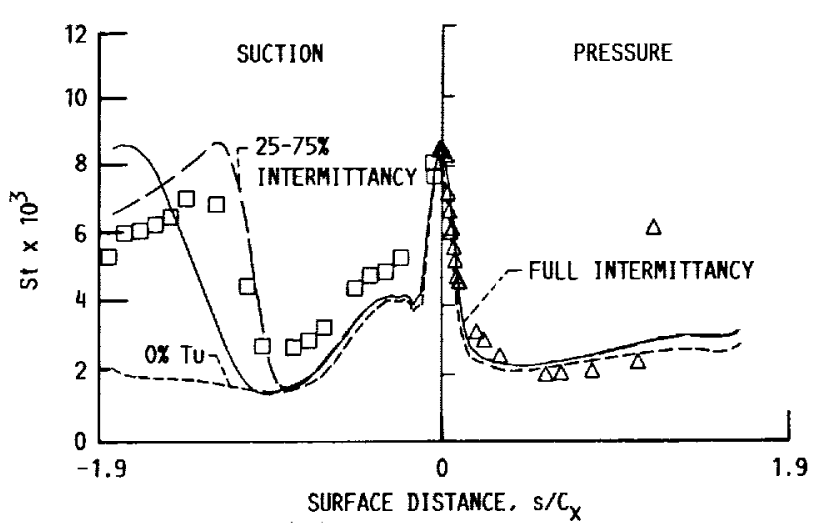

(d) STANTON MUMBER AT 63 PERCENT OF DESIGN Re, NO TURBULENCE GRID.

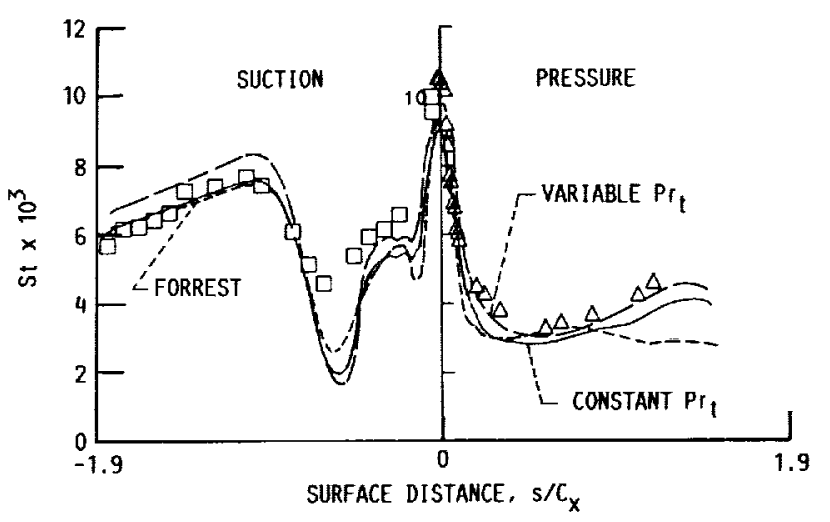

(e) STANTON NUMBER AT 62 PERCENT OF DESIGN Re, TURBULENCE GRID.

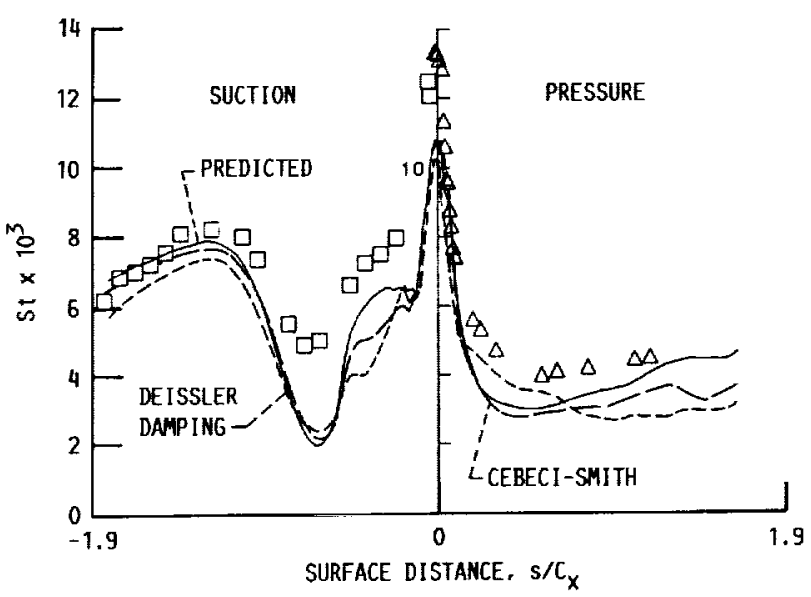

(f) Stanton number at 37 PERCENT OF DESIGN Re, TURBULENCE GRID.

FIGURE 7. - PRESSURE DISTRIBUTION AND STANTON NUMBERS FOR STATOR - 1 OF DRING ET AL. 

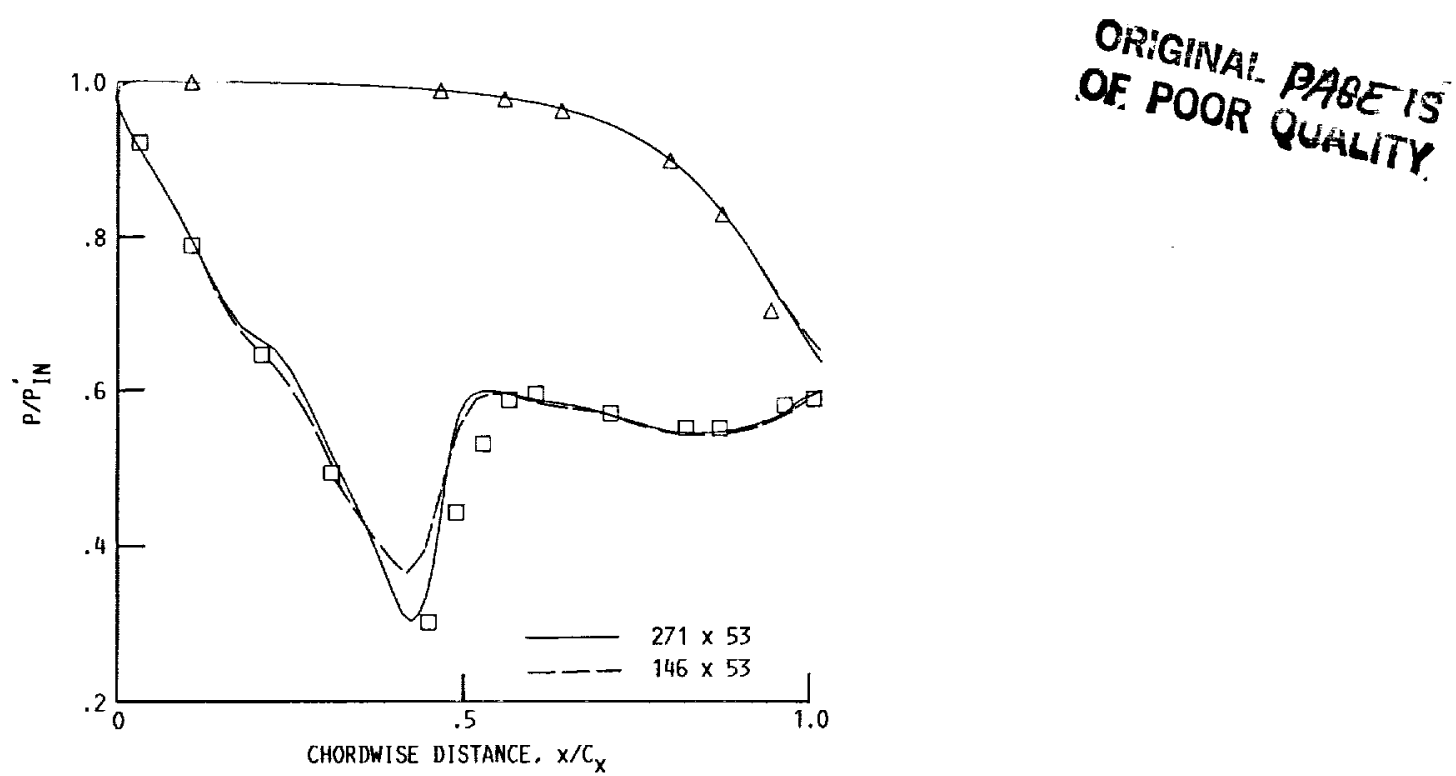

(a) SURFACE PRESSURES AT $P_{E X} / P_{\text {IN }}^{\prime}=0.582$.

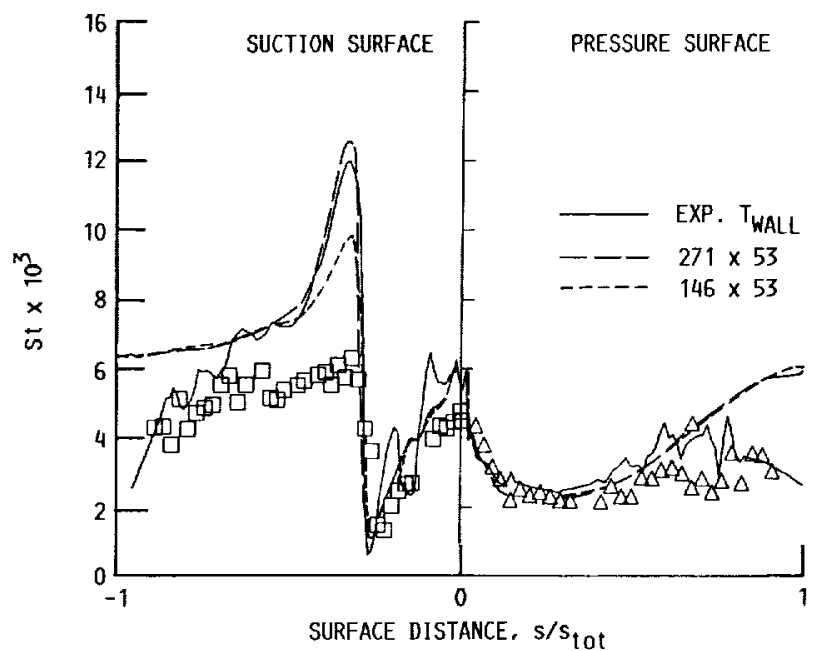

(b) STANTON NUMBER AT $\operatorname{Re}_{C-I N}=4.9 \times 10^{5}, P_{E X} / P_{I N}^{\prime}=0.582$.

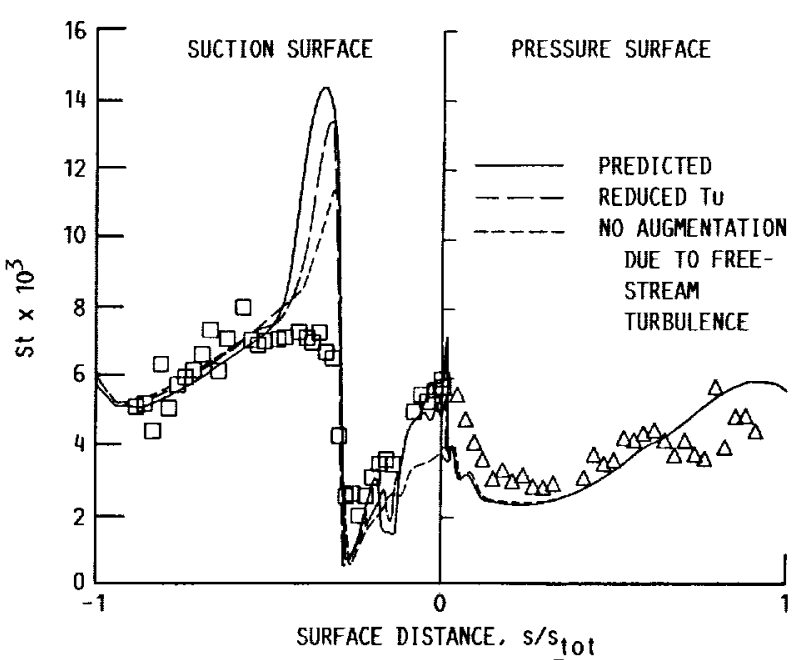

(d) STANTON NUMBER AT $\mathrm{Re}_{\mathrm{C} \text {-IN }}=6.4 \times 10^{5}, \mathrm{P}_{\text {EX }} / \mathrm{P}^{\prime}{ }_{\text {IN }}=0.490$.

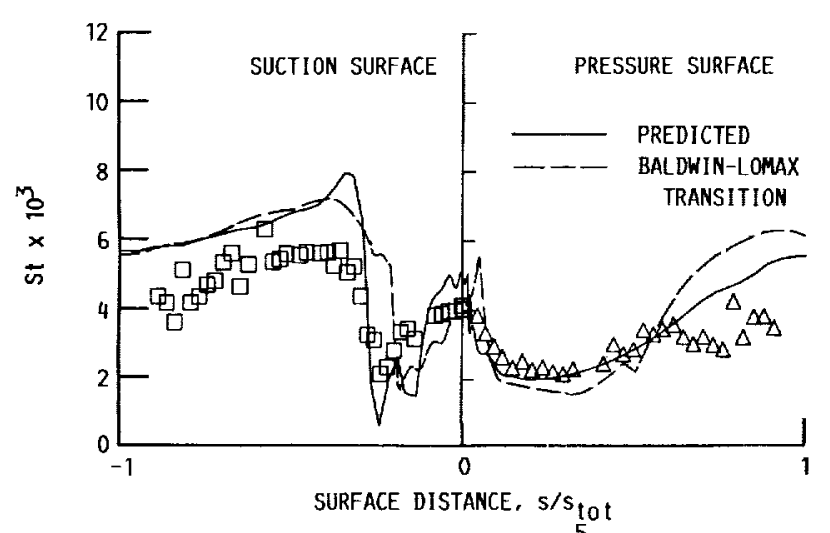

(c) StANTON NUMBER AT $\mathrm{Re}_{C-I N}=7.1 \times 10^{5}, \mathrm{P}_{\mathrm{EX}} / \mathrm{P}^{\prime}{ }_{\text {IN }}=0.582$.

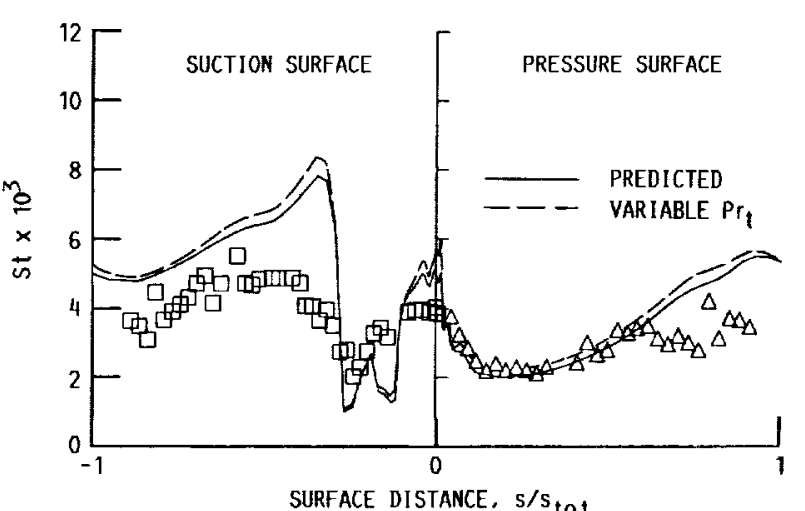

(e) STANTON NUMBER AT $\operatorname{Re}_{C \text {-IN }}=7.1 \times 10^{5}, \mathrm{P}_{\mathrm{EX}^{\prime}} \mathrm{P}_{\text {IN }}^{\prime}=0.490$.

FIGURE 8, - PRESSURE DISTRIBUTION AND STANTON NUMBERS FOR MARK II STATOR OF HYLTON ET AL. 


\section{ORIGINAL PAGE IS OF POOR QUALITY}

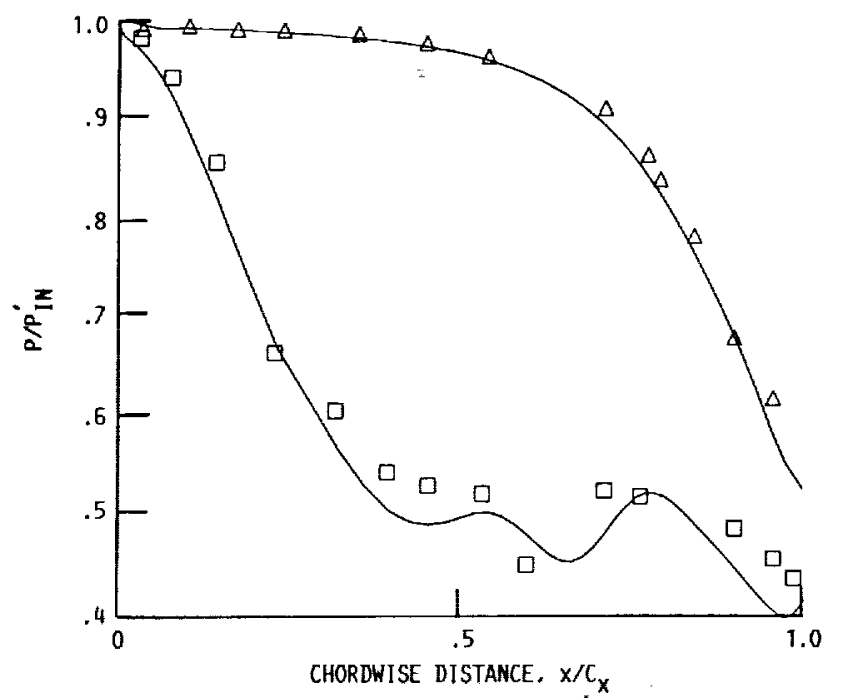

(a) SURFACE PRESSURES AT $P_{E X} / P_{I N}^{\prime}=0.490$.

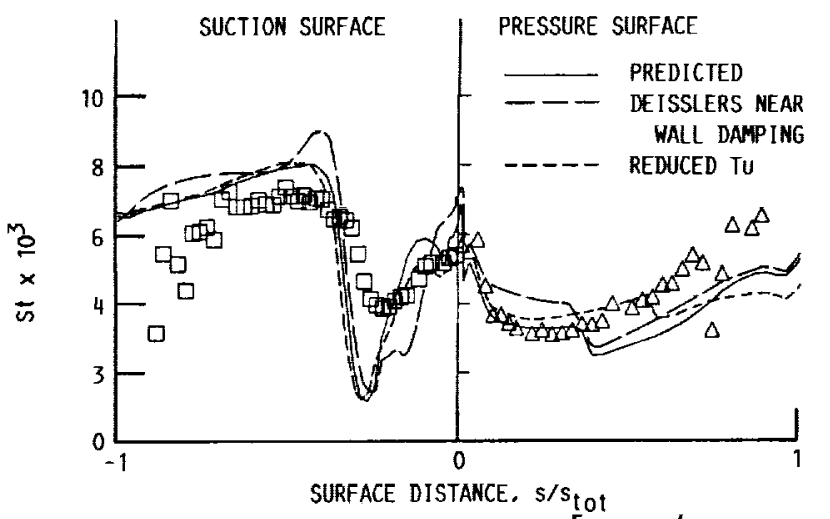

(b) STANTON NUMBER AT $\mathrm{Re}_{\mathrm{C}-\mathrm{IN}}=3.8 \times 10^{5}, \mathrm{P}_{\mathrm{EX}} / \mathrm{P}_{\text {IN }}^{\prime}=0.582$.

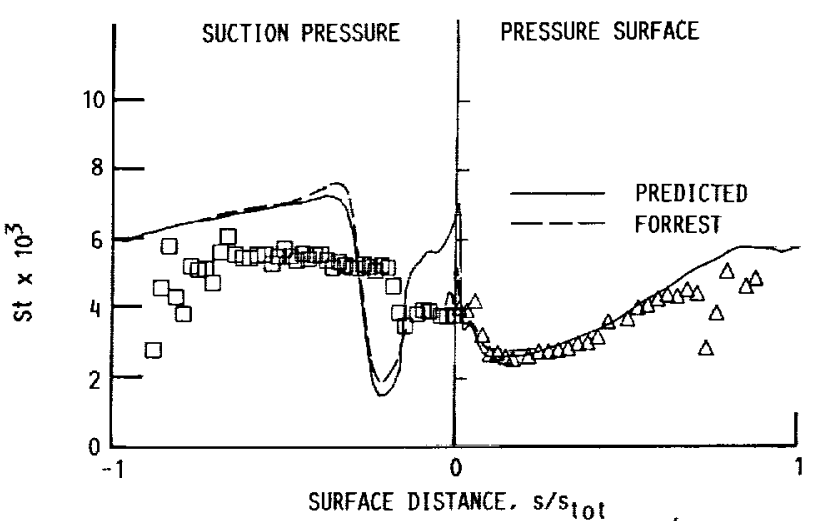

(c) STANTON NUMBER AT RE ${ }_{C-I N}=6.4 \times 10^{5} . P_{E X} / P_{I N}^{\prime}=0.582$.

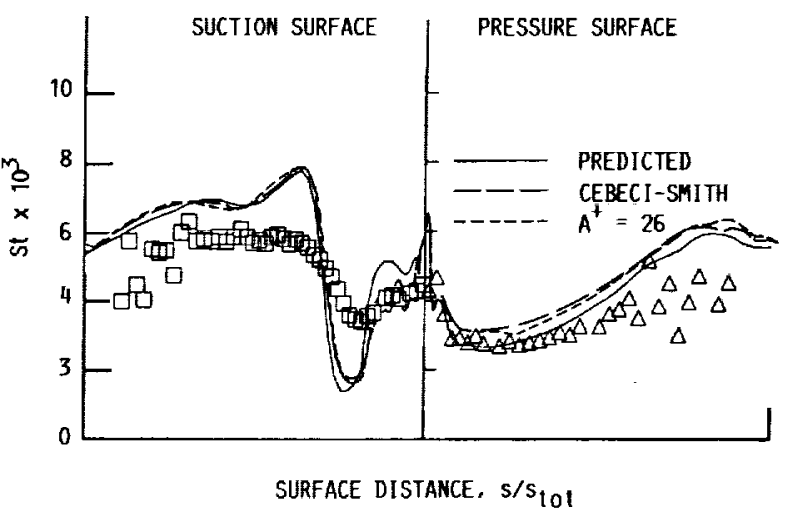

(d) Stanton number at $\operatorname{Re}_{C-I N}=5.1 \times 10^{5}, P_{E X} / P_{I N}^{\prime}=0.490$.

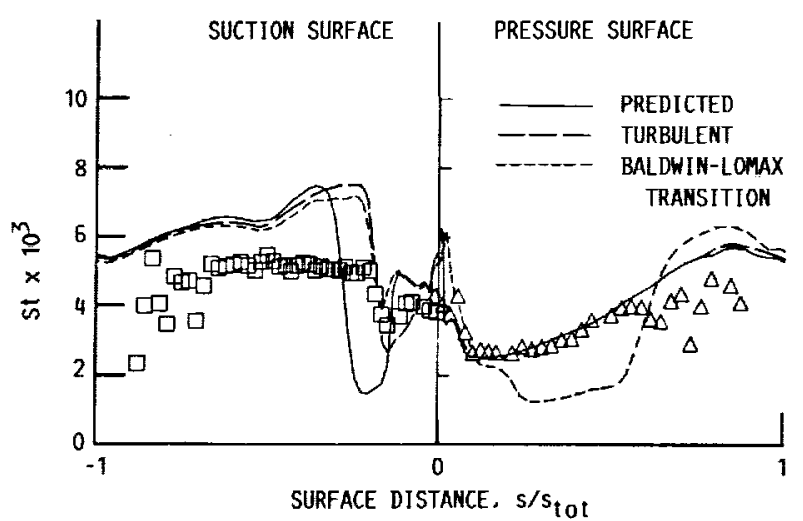

(e) STANTON NUMBER AT $R^{C} C$-IN $=6.4 \times 10^{5}, P_{E X} / P_{\text {IN }}^{\prime}=0.490$.

FIGURE 9. - PRESSURE DISTRIBUTION AND STANTON NUHBERS FOR C3X STATOR OF HYLTON ET AL. 


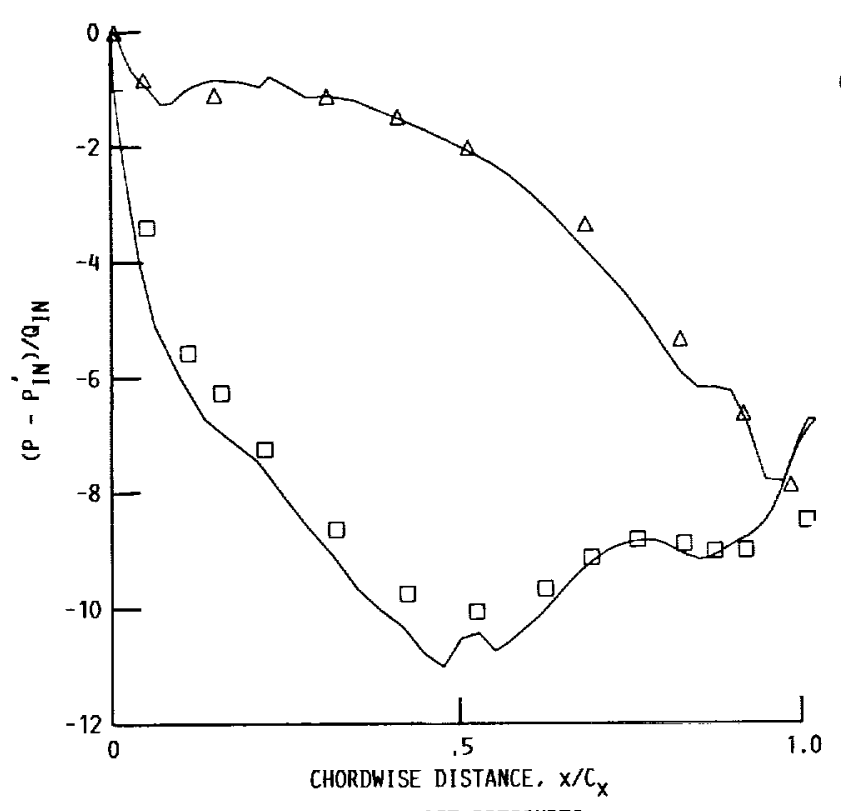

\section{ORIGINAL PAGE IS
OF POOR QUALITY}

(a) SURFACE PRESSURES.

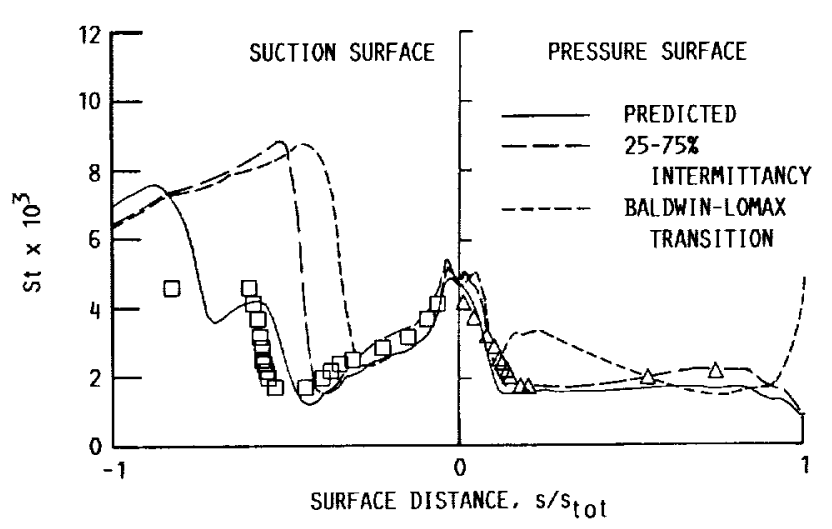

(b) STANTON NUMBER AT DESIGN Re, NO TURBULENCE GRID.

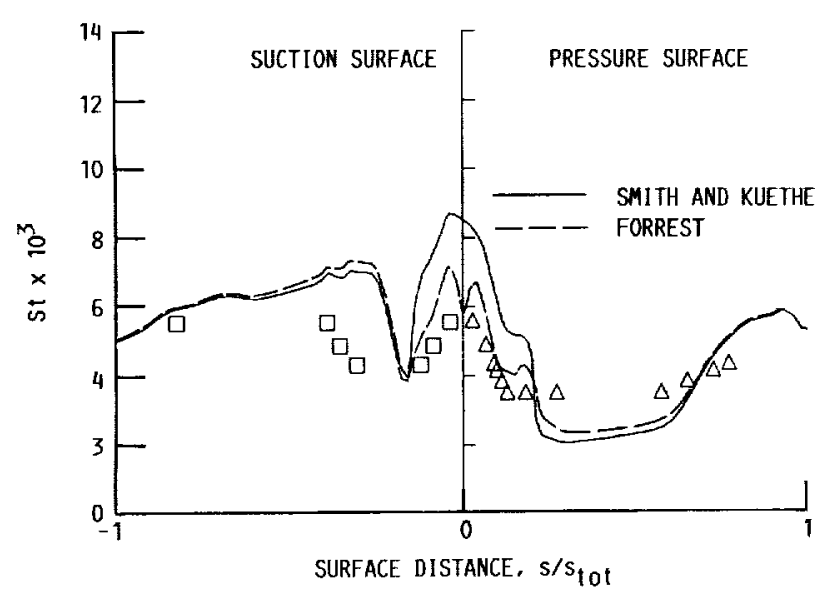

(c) STANTON NUMBER AT DESIGN Re, TURBULENCE GRID.

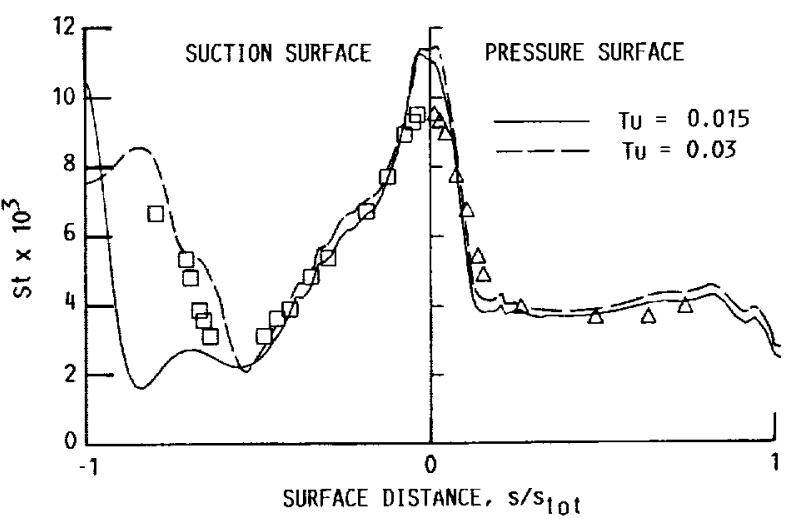

(d) STANTON NUMBER AT 22 PERCENT OF DESIGN Re, No TURBULENCE GRID.

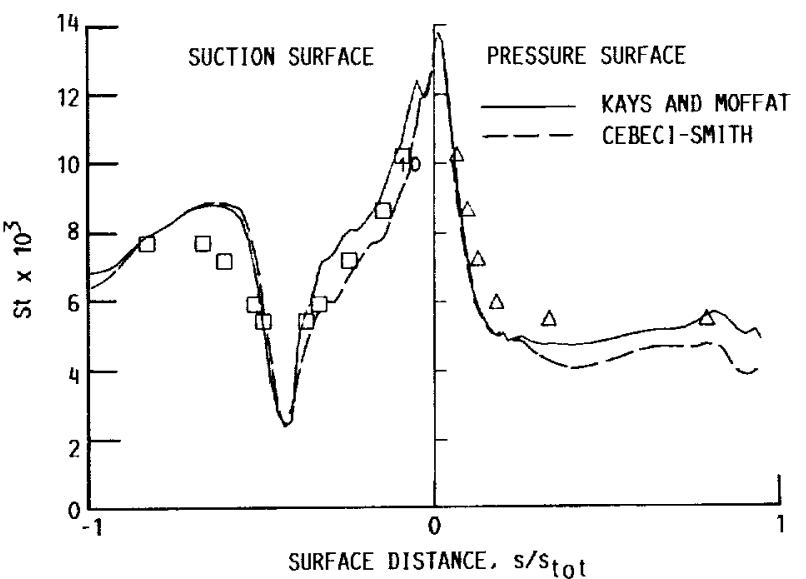

(e) STANTON NUMBER AT 22 PERCENT OF DESIGN Re, TURBULENCE GRID.

FIGURE 10. - PRESSURE DISTRIBUTION AND STANTON NUMBERS FOR STATOR OF HIPPENSTEELE ET AL. 


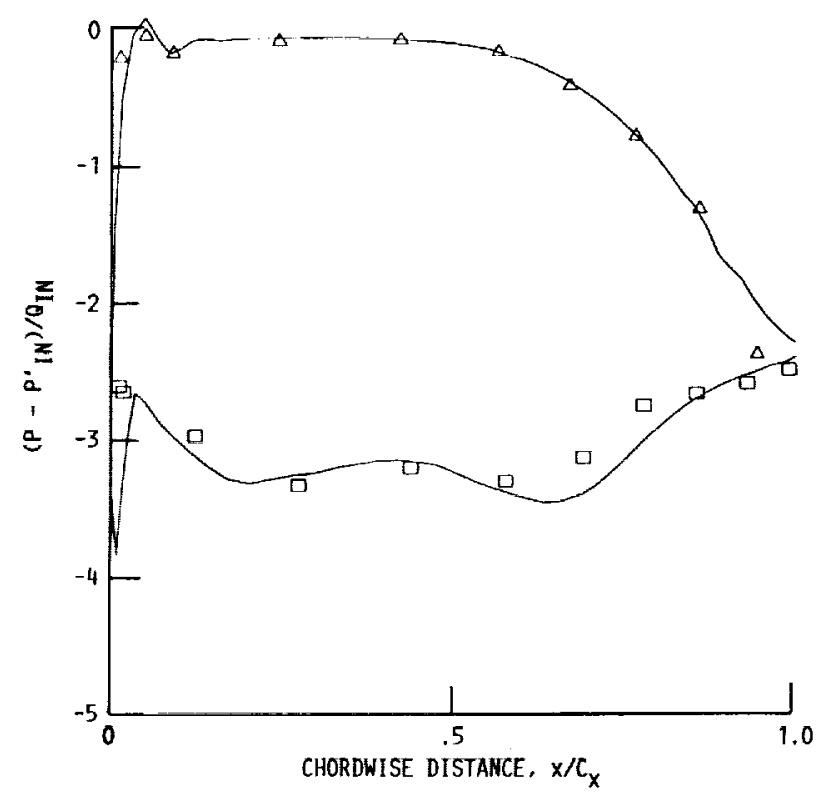

(a) SURFACE PRESSURES AT $\Phi=0.78$.

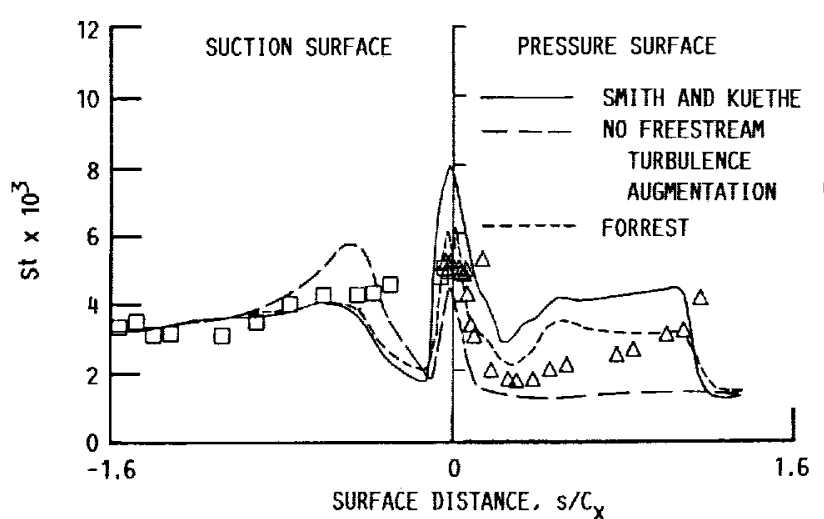

(b) STANTON NUMBERS AT $\Phi=0.78$.

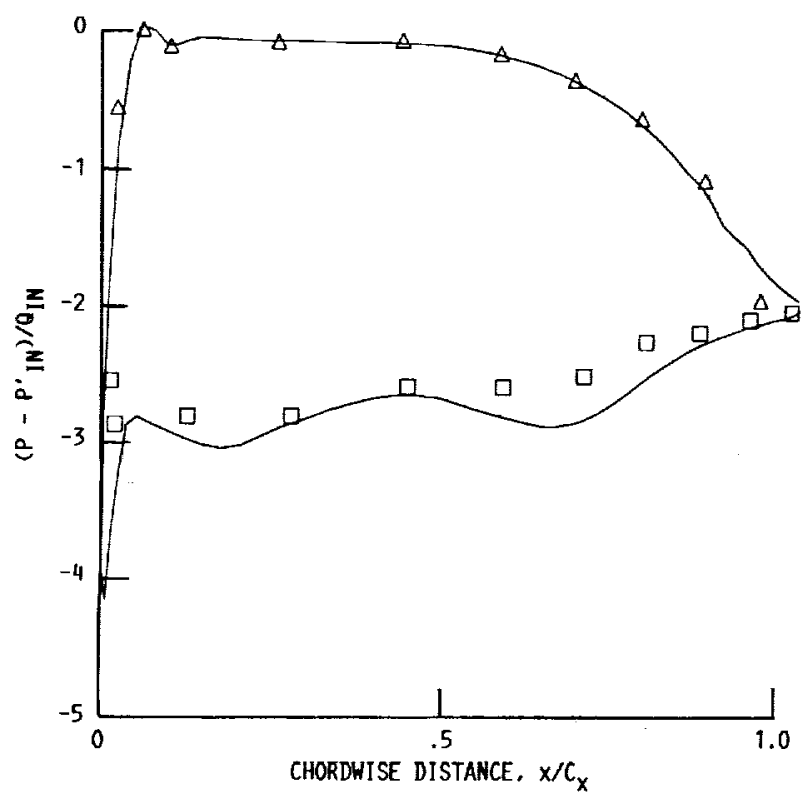

(c) SURFACE PRESSURES AT $\phi=0.96$.

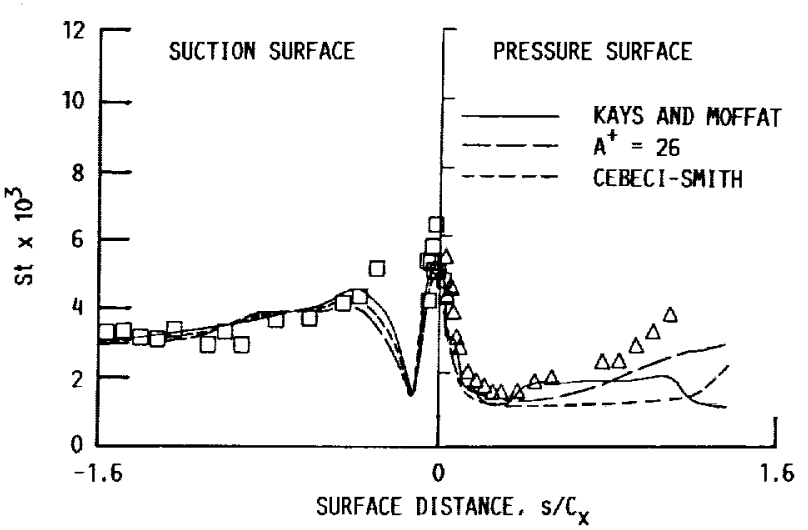

(d) STANTON NUMBERS AT $\Phi=0.96$.

FIGURE 11. - PRESSURE DISTRIBUTION AND STANTON NUMBERS FOR ROTOR OF DRING ET AL. 


\section{ORIGINAL \\ OF POOR QUALITS}

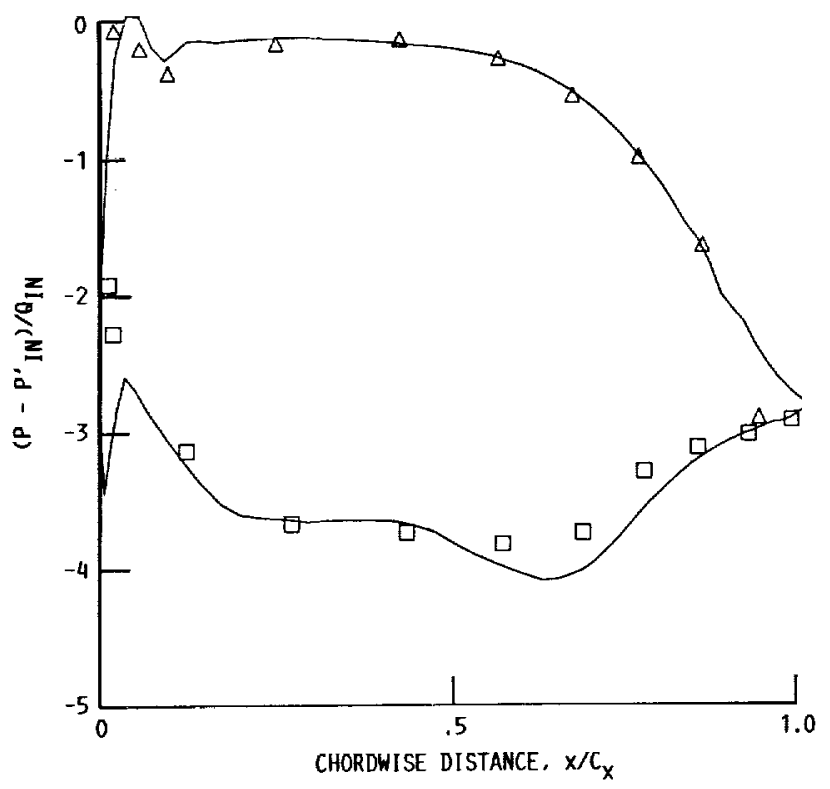

(e) SURFACE PRESSURES AT $\emptyset=0.68$.

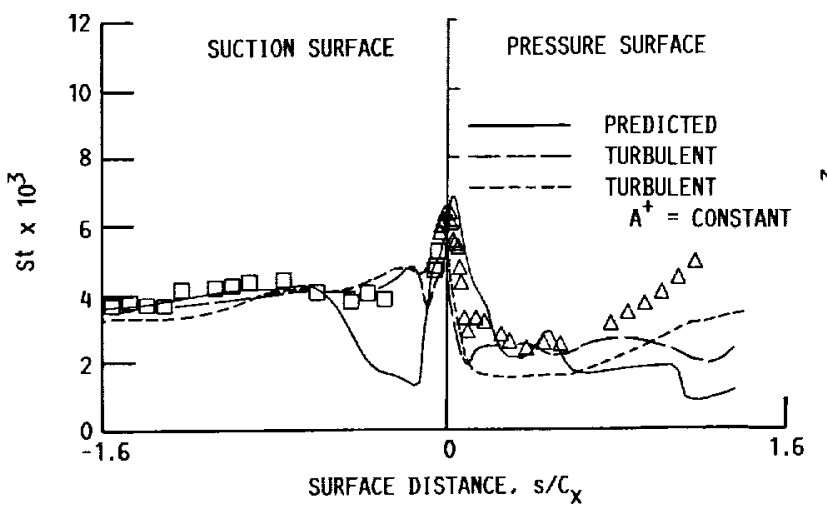

(f) STANTON NUMBERS AT $\emptyset=0.68$.

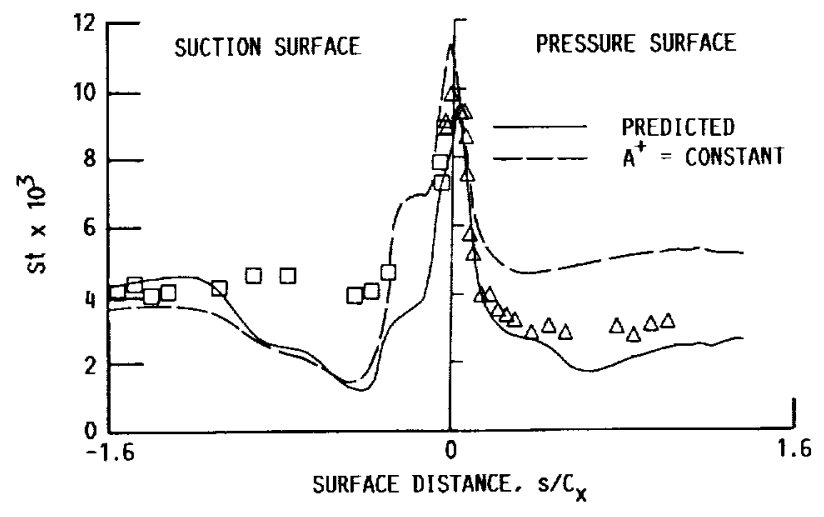

(g) STANTON NUMBER aT 36 PERCENT OF DESIGN Re.

FIGURE 11. - CONCLUDED. 


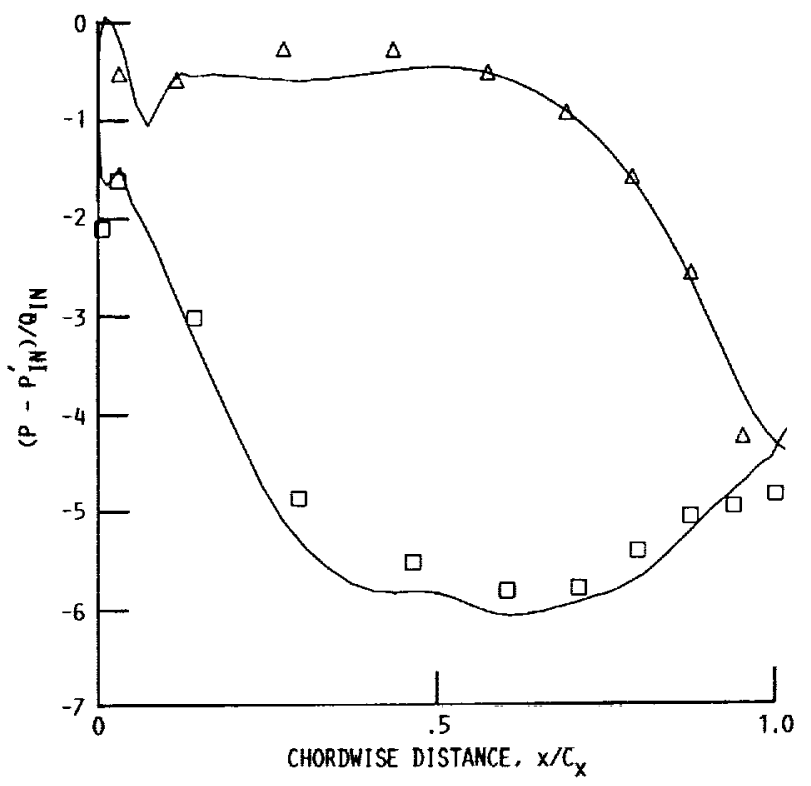

(a) SURFACE PRESSURES AT $\Phi=0.78$.

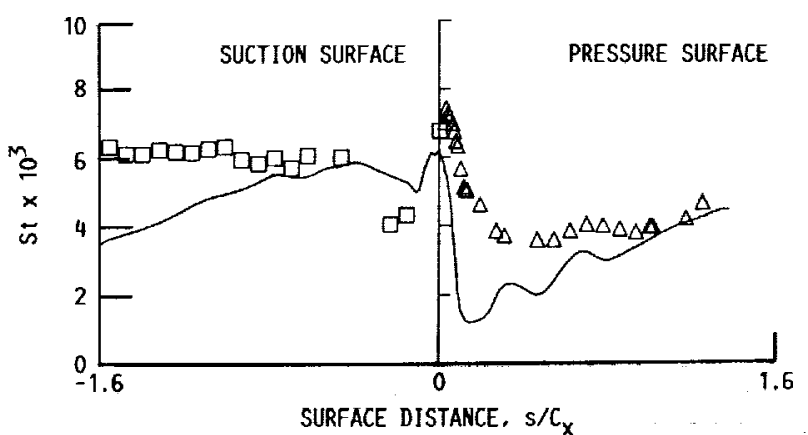

(b) STANTON NUMBERS AT $\Phi=0.78$.

FIGURE 12. - PRESSURE DISTRIBUTION AND STANTON NUMBERS FOR SECOND STATOR OF DRING ET AL. 


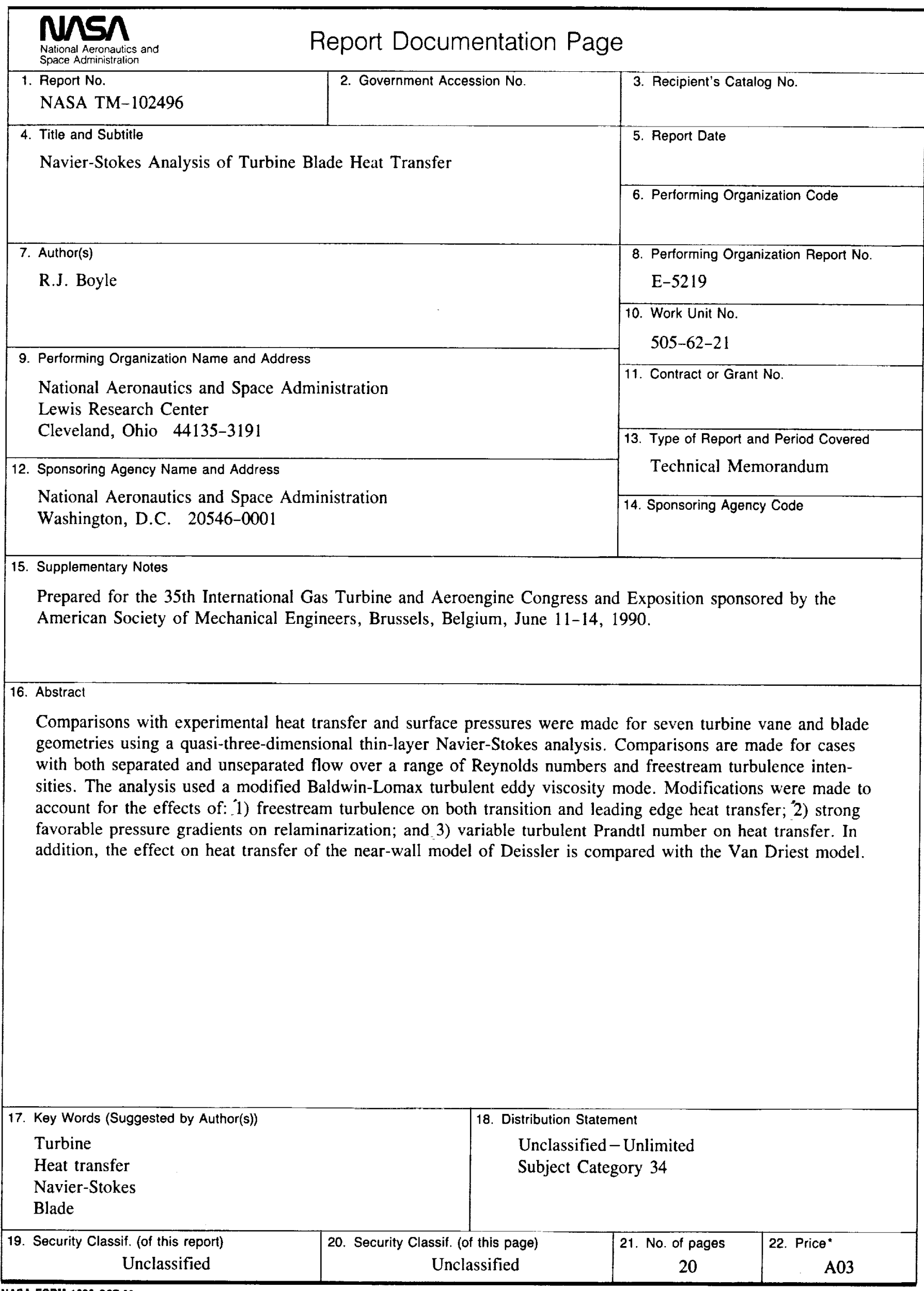




\section{ORIGNAL PAGE IS
OF. POOR QUALITY}

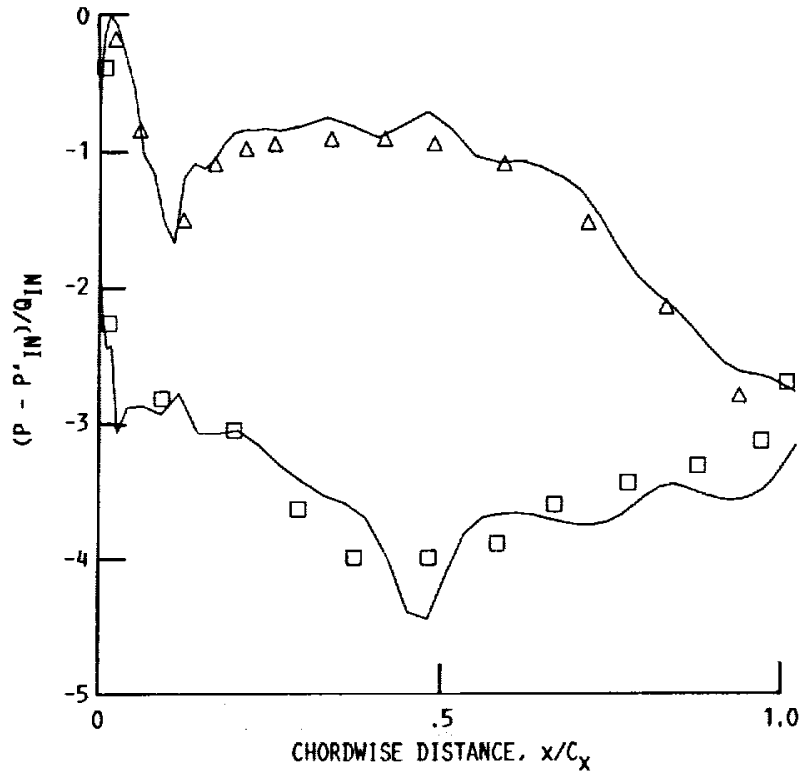

(a) SURFACE PRESSURES.

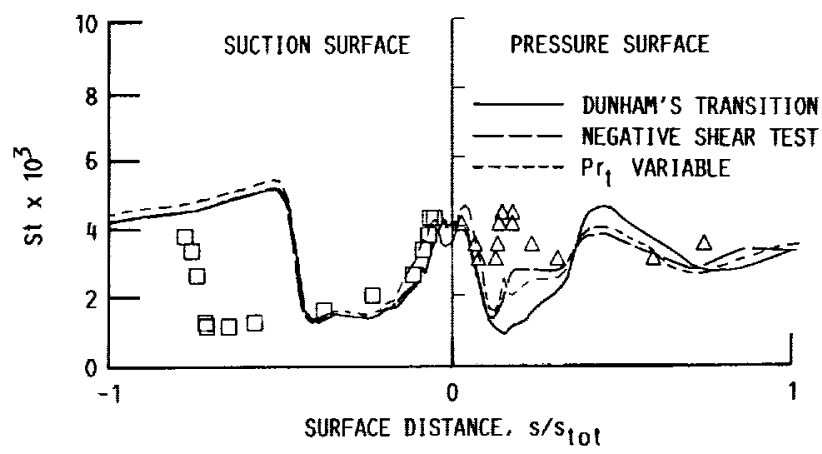

(b) STANTON NUMBER AT DESIGN RE, NO TURBULENCE GRID.

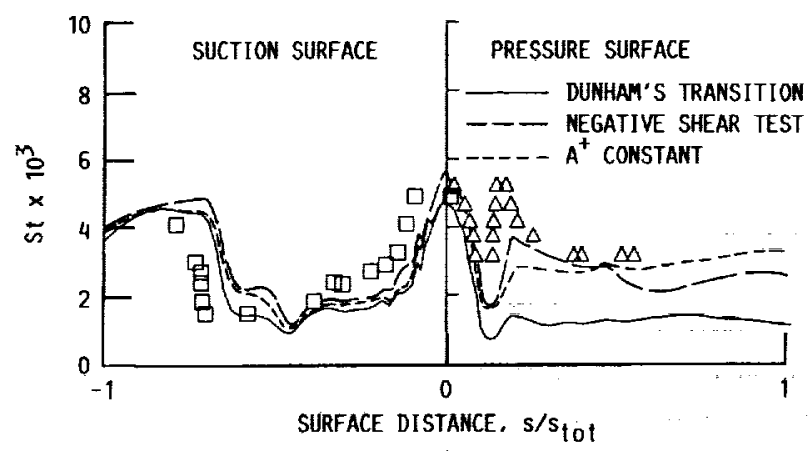

(c) STANTON MUMBER at 55 PERCENT OF DESIGN Re.

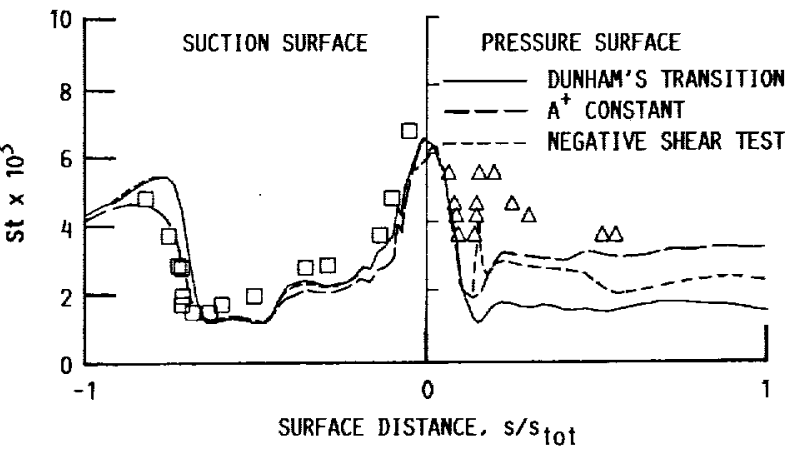

(d) STANTON NUMBER AT 37 PERCENT OF DESIGN Re.

FIGURE 13. - PRESSURE DISTRIBUTION AND STANTON NUMBERS FOR ROTOR OF HIPPENSTEELE ET AL. 